\title{
In vitro and in vivo evaluation of biologically synthesized silver nanoparticles for topical applications: effect of surface coating and loading into hydrogels
}

\author{
This article was published in the following Dove Press journal: \\ International Journal of Nanomedicine \\ 23 January 2017 \\ Number of times this article has been viewed
}

\author{
Aml I Mekkawy' \\ Mohamed A El-Mokhtar ${ }^{2}$ \\ Nivien A Nafady ${ }^{3}$ \\ Naeima Yousef ${ }^{3}$ \\ Mostafa A Hamad ${ }^{4}$ \\ Sohair M El-Shanawany ${ }^{5}$ \\ Ehsan $\mathrm{H}_{\text {Ibrahim }}{ }^{5}$ \\ Mahmoud Elsabahy ${ }^{5-8}$ \\ 'Department of Pharmaceutics \\ and Clinical Pharmacy, Faculty of \\ Pharmacy, Sohag University, Sohag, \\ ${ }^{2}$ Department of Microbiology and \\ Immunology, Faculty of Medicine, \\ ${ }^{3}$ Department of Botany and \\ Microbiology, Faculty of Science, \\ ${ }^{4}$ Department of Surgery, Faculty \\ of Medicine, ${ }^{5}$ Department of \\ Pharmaceutics, Faculty of Pharmacy, \\ ${ }^{6}$ Assiut International Center of \\ Nanomedicine, Al-Rajhi Liver \\ Hospital, Assiut University, Assiut, \\ Egypt; ' ${ }^{7}$ aboratory for Synthetic- \\ Biologic Interactions, Department \\ of Chemistry, Texas A\&M University, \\ College Station, TX, USA; ${ }^{8}$ Misr \\ University for Science and Technology, \\ 6th of October, Egypt
}

\begin{abstract}
In the present study, silver nanoparticles (AgNPs) were synthesized via biological reduction of silver nitrate using extract of the fungus Fusarium verticillioides (green chemistry principle). The synthesized nanoparticles were spherical and homogenous in size. AgNPs were coated with polyethylene glycol (PEG) 6000, sodium dodecyl sulfate (SDS), and $\beta$-cyclodextrin ( $\beta$-CD). The averaged diameters of AgNPs were 19.2 $\pm 3.6,13 \pm 4,14 \pm 4.4$, and $15.7 \pm 4.8 \mathrm{~nm}$, for PEG-, SDS-, and $\beta$-CD-coated and uncoated AgNPs, respectively. PEG-coated AgNPs showed greater stability as indicated by a decreased sedimentation rate of particles in their water dispersions. The antibacterial activities of different AgNPs dispersions were investigated against Gram-positive bacteria (methicillin-sensitive and methicillin-resistant Staphylococcus aureus) and Gram-negative bacteria (Escherichia coli) by determination of the minimum inhibitory concentrations (MICs) and minimum bactericidal concentrations (MBCs). MIC and MBC values were in the range of $0.93-7.5$ and $3.75-15 \mu \mathrm{g} / \mathrm{mL}$, respectively, which were superior to the reported values in literature. AgNPs-loaded hydrogels were prepared from the coated-AgNPs dispersions using several gelling agents (sodium carboxymethyl cellulose [Na CMC], sodium alginate, hydroxypropylmethyl cellulose, Pluronic F-127, and chitosan). The prepared formulations were evaluated for their viscosity, spreadability, in vitro drug release, and antibacterial activity, and the combined effect of the type of surface coating and the polymers utilized to form the gel was studied. The in vivo wound-healing activity and antibacterial efficacy of $\mathrm{Na} \mathrm{CMC}$ hydrogel loaded with PEG-coated AgNPs in comparison to the commercially available silver sulfadiazine cream $\left(\right.$ Dermazin $^{\circledR}$ ) were evaluated. Superior antibacterial activity and woundhealing capability, with normal skin appearance and hair growth, were demonstrated for the hydrogel formulations, as compared to the silver sulfadiazine cream. Histological examination of the treated skin was performed using light microscopy, whereas the location of AgNPs in the skin epidermal layers was visualized using transmission electron microscopy.
\end{abstract}

Keywords: silver nanoparticles, green synthesis, coating agents, hydrogel, wound healing, antibacterial activity

\section{Introduction}

Multidrug resistance is commonly developed against several pathogenic bacteria consequent to the use of several antibiotics. ${ }^{1-4}$ Recovery from multidrug-resistant infections is a problematic issue $e^{5,6}$ and requires multiple treatments with broad-spectrum antibiotics, which is usually associated with toxicity and high cost. ${ }^{6}$ Methicillinresistant Staphylococcus aureus (MRSA) is the main cause of worldwide nosocomial
Department of Pharmaceutics,

Faculty of Pharmacy, Assiut University,

71515 Assiut, Egypt

Tel +20 I0 00607466

Fax +20 8820807 II

Email mahmoud.elsabahy@chem. tamu.edu
International Journal of Nanomedicine 2017:12 759-777

759

Dovepress f in 0

http://dx.doi.org/10.2147/IN S.S124294 (c) (1) (8) $\odot 2017$ Mekkawy et al. This work is published and licensed by Dove Medical Press Limited. The full terms of this license are available at https://www.dovepress. com/terms.php

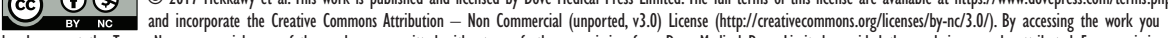
hereby accept the Terms. Non-commercial uses of the work are permitted without any further permission from Dove Medical Press Limited, provided the work is properly attributed. For permision for commercial use of this work, please see paragraphs 4.2 and 5 of our Terms (htpps//www.dovepress.com/terms.php). 
infections and usually associated with increasing mortality and morbidity rates. ${ }^{7}$ In general, $S$. aureus causes superficial lesions in human skin, localized abscesses, septicemia, pneumonia, and bacteremia. ${ }^{8}$

Historically, silver was one of the frequently used antibacterial agents before the introduction of antibiotics. ${ }^{9}$ Silver compounds, silver ions, and silver nanoparticles (AgNPs) have been validated extensively for their antibacterial, antifungal, and antiviral activities. ${ }^{2,10-13}$ Silver ions in silvercontaining creams (such as silver sulfadiazine) are reported to exhibit high toxicity when applied to denuded skin due to the increased absorption of silver ions. ${ }^{2}$ In addition, they have low stability due to inactivation by complexation with available counter ions and subsequent precipitation. ${ }^{3}$ Among several tested metallic nanoparticles, AgNPs were found to be the most effective antimicrobial agent against bacteria, viruses, and other eukaryotic microorganisms. ${ }^{14}$ AgNPs can be used as an effective broad-spectrum antibacterial agent against Gram-negative and Gram-positive bacteria including antibiotic-resistant bacteria. ${ }^{15}$ Silver attacks multiple targets in the microorganisms, and therefore decreases their ability to develop resistance. ${ }^{13,16,17}$ AgNPs exhibit higher toxicity to microorganisms than mammalian cells. ${ }^{18}$ The broad-spectrum antibacterial effectiveness of AgNPs is due to their small size that enhances the accumulation in the microbial membrane and thus results in disruption and loss of integrity of the microbial membrane..$^{8,19-21}$

AgNPs are fabricated by different methods including chemical, physical, and green methods. ${ }^{1,3,22,23}$ Chemical and physical methods are usually expensive, with low production rates, and are not ecofriendly due to the toxicity of the used chemical-reducing agents and capping agents. ${ }^{4}$ On the other hand, green chemistry method is preferred because the synthesized products are obtained from natural extracts. ${ }^{24}$ Green chemistry involves different biological methods for the synthesis of AgNPs which employ plants extract or microorganisms, such as fungi and bacteria. ${ }^{1,20,24,25}$

To prevent aggregation of particles, different coating materials, such as carboxylic acids, polymers, polysaccharides, and surfactants, have been exploited to increase stability of the particles. ${ }^{26}$ Polyethylene glycols (PEGs) are stable, hydrophilic, and nonirritant to the skin, ${ }^{27}$ and have been used as an organic capping agent to stabilize AgNPs and control further growth of the particles via trapping of seeds and steric repulsion. ${ }^{28}$

Topical application of AgNPs for treatment of skin infections could be more effective if the particles are suspended in a hydrogel matrix, as compared to free particles suspended in water. Hydrogels are easily applied and removed with improved patient compliance. Various gelling agents were reported in literature for the preparation of antimicrobial hydrogels due to their antibacterial activity per se, which might potentiate the efficacy of the loaded antimicrobial agents. Several authors reported the preparation of topically applied formulations intended for the delivery of AgNPs. ${ }^{21,24,29,30}$

The present work aimed at biological synthesis of AgNPs in a simple, ecofriendly, and cost-effective manner using fungus Fusarium verticillioides ASU1 (KT587649). A comparative detailed study based on the effect of three factors on AgNPs activity was provided. First, effect of different coating agents, including PEG 6000, sodium dodecyl sulfate (SDS), and $\beta$-cyclodextrin ( $\beta$-CD), on AgNPs stability and antimicrobial activity was investigated. Second, various gelling agents, namely sodium carboxymethyl cellulose ( $\mathrm{Na} \mathrm{CMC}$ ), sodium alginate ( $\mathrm{Na}$ alginate), hydroxypropylmethyl cellulose (HPMC), Pluronic F-127, and chitosan, were used in the preparation of AgNPs-loaded hydrogels to aid in the topical application of AgNPs. The effect of coating type and gelling agent on the viscosity, spreadability, in vitro release profile, and antibacterial activity of the medicated hydrogels was studied. Third, effect of type of bacteria on the activity of AgNPs was evaluated. Gramnegative (Escherichia coli) and Gram-positive (MRSA and methicillin-sensitive $S$. aureus [MSSA]) bacteria were used to evaluate the antimicrobial activities of the various formulations. Efficacy of a selected 0.1\% AgNPs-loaded hydrogel was studied in vivo versus the commercially available $1 \%$ silver sulfadiazine cream (Dermazin ${ }^{\circledR}$ ), and wound-healing and antimicrobial activities in rats and in MRSA-infected mouse model were compared.

\section{Materials and methods Materials}

Silver nitrate $\left(\mathrm{AgNO}_{3}\right), \beta-\mathrm{CD}$, Pluronic F-127, and HPMC were purchased from Sigma Aldrich (St Louis, MO, USA). $\mathrm{Na} \mathrm{CMC}$ of molecular weight $30,000 \mathrm{Da}$, propylene glycol (PG), and PEG 6000 were purchased from Adwic, EL-Nasr Pharmaceutical Chemicals (Cairo, Egypt). SDS was purchased from Novartis (Basel, Switzerland). Chitosan of molecular weight 100,000-300,000 Da was purchased from Acros Organics (Geel, Belgium). Na alginate was purchased from Judex Laboratory Reagent (Sudbury, UK).

\section{Biological synthesis of AgNPs}

\section{Microorganism and media}

The strain $F$. verticillioides ASU1 (KT587649), isolated from Zea mays seeds, was used in this study. The strain was 
maintained on potato dextrose agar medium at $28^{\circ} \mathrm{C} \pm 2^{\circ} \mathrm{C}$ and stored at $4^{\circ} \mathrm{C}$ for subsequent study.

\section{Biosynthesis of AgNPs}

For the synthesis of AgNPs, the biomass of fungus F. verticillioides ASU1 (KT587649) was prepared by growing the fungus in a potato dextrose broth medium. Flasks were inoculated, incubated on an orbital shaker at $28^{\circ} \mathrm{C} \pm 2^{\circ} \mathrm{C}$, and agitated at $150 \mathrm{rpm}$ for $72 \mathrm{~h}$. After complete incubation, the biomass was harvested by filtering through filter paper followed by repeated washing with distilled water to remove any medium components from the biomass. About $15 \mathrm{~g}$ (wet weight) was brought in contact with $100 \mathrm{~mL}$ of sterilized double-distilled water for $24 \mathrm{~h}$ at $28^{\circ} \mathrm{C} \pm 2^{\circ} \mathrm{C}$ in a $250 \mathrm{~mL}$ Erlenmeyer flask and agitated again at $150 \mathrm{rpm}$. The cell filtrate was obtained after the incubation by passing it through Whatman ${ }^{\circledR}$ filter paper Number 1 . The filtrate was treated with aqueous $1 \mathrm{mM} \mathrm{AgNO}_{3}$ solution in an Erlenmeyer flask and incubated at room temperature. Cell-free filtrate without $\mathrm{AgNO}_{3}$ solution was also run as a control. ${ }^{31}$ AgNPs dispersion was then centrifuged at 14,000 rpm for $20 \mathrm{~min}$. The supernatant was discarded, and the pellets were redispersed in distilled water, and washed three times with sterilized distilled water to remove the free entities and unbound biological molecules from AgNPs.

\section{Characterization of the synthesized AgNPs}

Atomic absorption spectroscopy (AAS)

The concentration of AgNPs in the suspensions was measured using the Buck Scientific atomic absorption spectrophotometer (Model 210 VGP; Norwalk, CT, USA) equipped with a silver hollow cathode lamp and air-acetylene flame. Standard silver solutions were also prepared and measured.

\section{X-ray diffraction (XRD)}

Crystalline structure of the biologically synthesized AgNPs powder was identified using a Philips X-ray diffractometer model PW 1710 (Philips, Amsterdam, the Netherlands) with $\mathrm{CuK}_{\alpha}$ radiation $(\lambda=1.5405 \AA)$, at an operating applied voltage of $40 \mathrm{kV}$ and $30 \mathrm{~mA}$ current, equipped with a graphite monochromator and automatic divergence slit. Measurements were swapped from $2 \theta=35^{\circ}$ to $2 \theta=80^{\circ}$ with a scanning speed of $0.06^{\circ} / \mathrm{min}$.

\section{UV-visible spectrophotometry}

The bioreduction of $\mathrm{AgNO}_{3}$ solution and formation of AgNPs by fungal extract was confirmed by scanning the resulted dispersion at 300-900 $\mathrm{nm}$ wavelength range using a double-beam spectrophotometer (Thermo Scientific Evolution $^{\text {TM }} 300$ UV-Vis Spectrophotometer; Thermo Fisher Scientific, Waltham, MA, USA). A strong absorption of electromagnetic waves was exhibited by metal nanoparticles in the visible range due to the surface plasmon resonance (SPR) effect.

\section{Transmission electron microscopy (TEM)}

A drop of the biologically synthesized AgNPs dispersion (100 $\mu \mathrm{g} / \mathrm{mL})$ was placed on a carbon-coated copper grid and dried at room temperature. TEM micrograph of the sample was taken using the JEOL TEM (Model 100 CX II; Tokyo, Japan) at the Electron Microscopy Unit, Assiut University, Egypt. Size and shape of AgNPs were studied.

\section{Coating of AgNPs}

Effect of coating agents on AgNPs sedimentation rate and antibacterial activity was studied using different coating agents, namely PEG 6000 (hydrophilic polymer), SDS (anionic surfactant), and $\beta-\mathrm{CD}$ (cyclic oligosaccharide polymer), which were added separately after the biological synthesis of AgNPs. PEG, SDS, and $\beta-C D$ solutions were prepared by dissolving their powders separately in distilled water. Then, the prepared solutions were added directly to the freshly prepared AgNPs suspension (500 $\mu \mathrm{g}$ AgNPs/mL) to obtain final concentrations of 5 and $10 \mathrm{mM}$ of each coating agent. The final solutions were sonicated for $1 \mathrm{~h}$ using an ultrasonicator (Crest Ultrasonics Corp., Trenton, NJ, USA). ${ }^{28,32,33}$ The ability of different coating agents, prepared at different concentrations, to maintain the nanoparticles dispersed in solutions and prevent their sedimentation over time was studied. Stability of AgNPs dispersions $(500 \mu \mathrm{g} / \mathrm{mL})$ was examined visually after $1,2,3,6,9$, and 12 months at $4^{\circ} \mathrm{C}$. Also, the coated AgNPs dispersions were scanned at 300-900 nm using a UV-visible spectrophotometer, and TEM micrographs were also taken as previously described.

\section{Dynamic light scattering (DLS) and zeta-potential measurements}

The mean hydrodynamic diameters and size distribution (polydispersity indices, PDIs) of the nanoparticles in water as a dispersant were measured using a Zetasizer Nano ZS instrument (Malvern Instruments, Malvern, UK) equipped with a backscattered light detector operating at $173^{\circ}$. The CONTIN program was used to extract size distributions from the autocorrelation functions. The zeta-potential values were determined by laser Doppler anemometry using a Malvern Zetasizer Nanoseries ZS. 


\section{Antibacterial activity assay}

\section{Bacterial strains and growth condition}

The following microbial strains were used: MSSA and MRSA, which are Gram-positive bacteria; and E. coli, which are Gram-negative bacteria. All bacterial strains were clinically isolated at the infection control unit (Assiut University Hospital). Strains were grown in Mueller-Hinton broth or Mueller-Hinton agar medium at $37^{\circ} \mathrm{C}$. A single isolated colony of each bacterium was picked from the agar plate culture and suspended in $0.9 \%(\mathrm{w} / \mathrm{v})$ sterile aqueous saline solution to prepare bacterial suspensions of $0.5 \mathrm{McF}$ arland standard and diluted to give a final concentration of $10^{8}$ colony-forming units (CFU)/mL.

\section{Minimum inhibitory concentration (MIC) and} minimum bactericidal concentration (MBC)

In order to investigate the antibacterial activity of AgNPs and the role of coating agents, MIC of AgNPs dispersions against clinically isolated bacteria was determined using microtiter broth dilution method according to the guidelines of the Clinical and Laboratory Standards Institute. ${ }^{34}$ Sterile 96-well rounded-bottom plates were used. AgNPs dispersions were sonicated before the experiment to ensure homogenous distribution of the particles. Mueller-Hinton broth $(100 \mu \mathrm{L})$ was dispensed into all wells of the microtiter plate. Each tested dispersion was added to the first well, and serial twofold dilutions were made. Bacterial dispersions $\left(5 \mu \mathrm{L}\right.$ of $\left.10^{6} \mathrm{CFU} / \mathrm{mL}\right)$ were added into all wells except for the sterility control blank. Plates were incubated at $37^{\circ} \mathrm{C}$ for $24 \mathrm{~h}$ and evaluated for the MIC by visual examination of the culture turbidity. In order to determine the MBC of the tested AgNPs dispersions, $5 \mu \mathrm{L}$ from the dilution that showed the MIC (no visible bacterial growth) and four of the more concentrated dilutions were plated, cultured at $37^{\circ} \mathrm{C}$ for $24 \mathrm{~h}$ without AgNPs supplementation, and counted to determine viable $\mathrm{CFU} / \mathrm{mL}$. The $\mathrm{MBC}$ is the lowest concentration that showed the same predetermined reduction in $\mathrm{CFU} / \mathrm{mL}$ when compared to the MIC dilution.

\section{Agar-well diffusion method}

Another method was also used to evaluate the antibacterial activity of the AgNPs. Bacterial suspensions (100 $\mu \mathrm{L})$ were mixed with Sabouraud agar $(20 \mathrm{~mL})$ in sterile petri dishes ( $9 \mathrm{~cm}$ in diameter), and the agar plates were allowed to solidify. After solidification, wells were made in the agar plates using a pore-maker of size $10 \mathrm{mM}$ and filled with the tested AgNPs dispersions $(200 \mu \mathrm{L}$ of $240 \mu \mathrm{g}$ AgNPs $/ \mathrm{mL})$ after sonication to ensure complete dispersion of the particles. Pure solutions of PEG, SDS, and $\beta$-CD were also used as positive growth controls. Plates were incubated at $37^{\circ} \mathrm{C}$ for $24 \mathrm{~h}$, and the diameters of inhibition zone were measured without subtracting the well diameter from the total inhibition zone diameter using a digital caliber. ${ }^{35,36}$ Inhibition zone diameter is an indicator of the antibacterial activity of AgNPs dispersions.

\section{Formulation of AgNPs-loaded hydrogels}

In order to make AgNPs dispersions applicable as topical treatment and to improve patient compliance, hydrogel formulations were prepared using five different polymergelling agents. The composition of the formulated hydrogels containing $500 \mu \mathrm{g}$ AgNPs per gram of hydrogel is shown in Table 1. As illustrated in the table, 25 formulations (F1-F25) were prepared by incorporating five different AgNPs dispersions (uncoated and 5 mM PEG-, 10 mM PEG-, 5 mM SDS-, and $5 \mathrm{mM} \beta$-CD-coated AgNPs) into each of five gelling polymers (Na CMC, Na alginate, HPMC, Pluronic F-127, and chitosan). Based on previous optimizations, PG (20\%, $\mathrm{w} / \mathrm{w}$ ) was added to all the prepared hydrogels to improve consistency and decrease the viscosity of the hydrogel formulations. In addition, PG enhances the hydrogen bonding between water and gelling agents, thus improving the AgNPs dispersion stability in the polymer network. ${ }^{37,38}$

The specified amounts $(3 \%, \mathrm{w} / \mathrm{w})$ of the gelling polymers (Na CMC, Na alginate, and HPMC) were added slowly, each separately, to a previously formed mixture of $20 \%$ (w/w) PG and specific volumes of AgNPs stock dispersions. Then, the mixtures were stirred continuously using a magnetic stirrer (Gallenkamp, Loughborough, UK) and allowed to soak overnight for complete polymer solvation. Twenty-five percent (w/w) Pluronic F-127 gels were prepared by the cold method described by Schmolka. ${ }^{39}$ The required amount of Pluronic F-127 was dissolved in PG and cold AgNP dispersions. Dispersions were left in a refrigerator overnight. A clear transparent gel was obtained when the dispersion was maintained at room temperature. Three percent $(\mathrm{w} / \mathrm{w})$ chitosan gel was prepared by addition of chitosan and $1 \%(\mathrm{v} / \mathrm{v})$ glacial acetic acid to specific amount of AgNPs dispersion and 20\% PG using a magnetic stirrer. The $\mathrm{pH}$ of chitosan hydrogel was adjusted to 5.5 by addition of $\mathrm{NaOH}$ solution.

\section{Evaluation of the prepared hydrogel formulations \\ Physical appearance}

The prepared formulations were inspected visually for their color and homogeneity.

\section{Viscosity and rheological behavior}

The flow rheological properties of the prepared topical formulations (F1-F25) were studied for blank and medicated 
Table I Composition of AgNPs hydrogels (500 $\mu \mathrm{g}$ AgNPs/g hydrogel). AgNPs were coated with 5 mM PEG 6000, 10 mM PEG 6000, $5 \mathrm{mM}$ SDS, and $5 \mathrm{mM} \beta-\mathrm{CD}$, and AgNPs-loaded hydrogels were prepared using various polymers ( $\mathrm{Na} \mathrm{CMC}, \mathrm{Na}$ alginate, HPMC, Pluronic F-127, and chitosan)

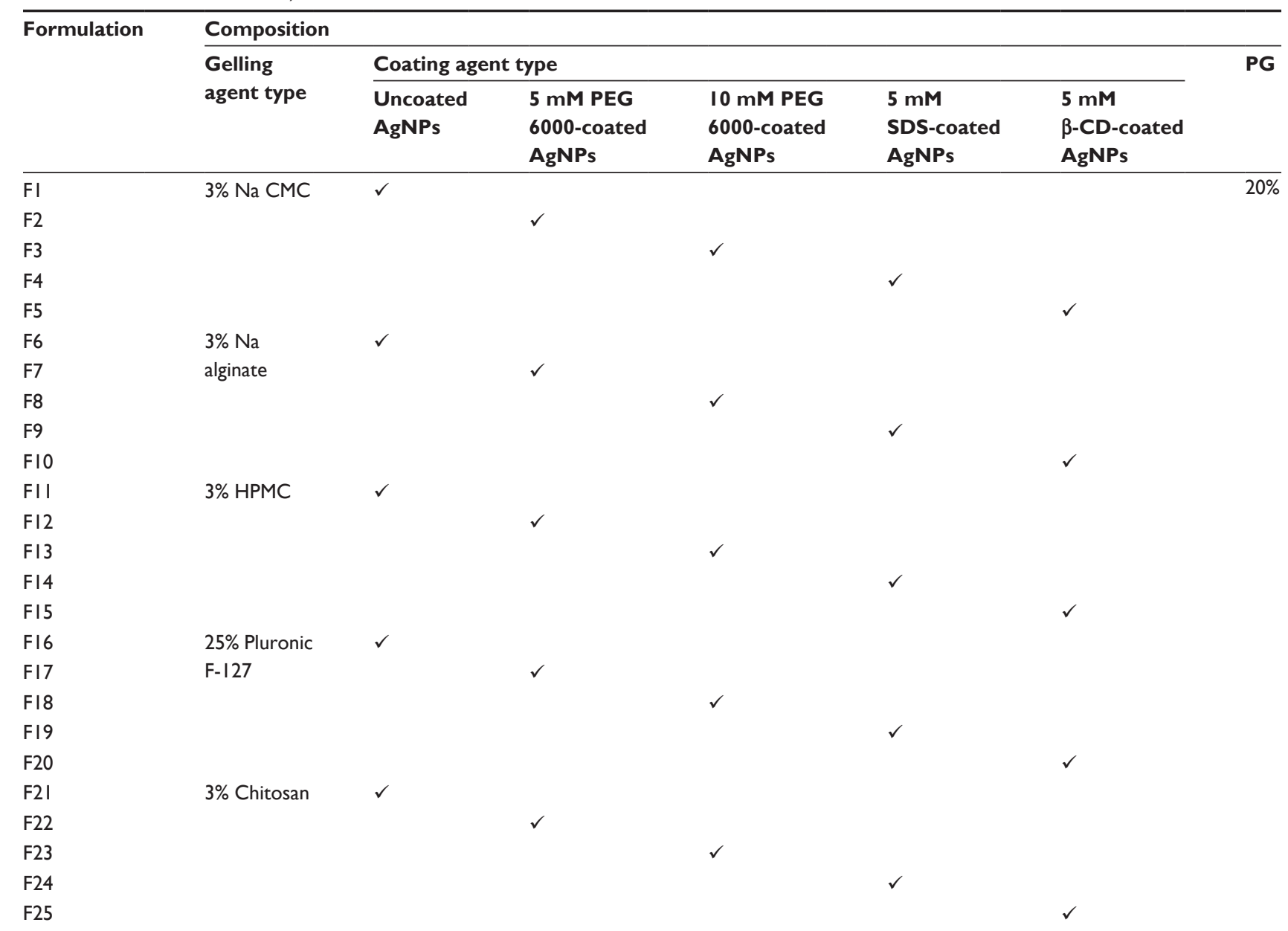

Abbreviations: AgNPs, silver nanoparticles; PEG, polyethylene glycol; SDS, sodium dodecyl sulfate; $\beta-C D, \beta$-cyclodextrin; Na CMC, sodium carboxymethyl cellulose; $\mathrm{Na}$ alginate, sodium alginate; HPMC, hydroxypropylmethyl cellulose; PG, propylene glycol.

formulations $(20 \mathrm{~g})$ at $25^{\circ} \mathrm{C}$ using a Brookfield DV-III ULTRA programmable rheometer, model RV, T-bar spindle numbers 95 (Brookfield Engineering Laboratories, Inc., Middleboro, MA, USA). Effect of AgNPs incorporation on the rheological characteristics of the hydrogel formulations was studied. Also, the effect of coating agents and gelling agents on viscosity of the hydrogel formulations was investigated. Measurements were performed over the range of speed settings from 5 to $50 \mathrm{rpm}$ with $1 \mathrm{~min}$ interval between each two successive speeds to generate a complete flow curve. The rheograms were generated by plotting viscosity readings in centipoises versus spindle speed (rpm).

\section{Spreadability}

Spreadability of the prepared formulations (F1-F25) was determined as reported previously. ${ }^{40}$ Each formulation $(0.25 \mathrm{~g})$ was moderately pressed between two glass slides and left for $5 \mathrm{~min}$. Diameters of the spreaded sample circles were measured in centimeter and taken as comparative values for spreadability. Results obtained were the average of three measurements.

\section{In vitro release}

The in vitro release of AgNPs from the prepared hydrogel formulations (F1-F25) was studied. One-gram sample of each formulation was accurately weighed and placed on nylon fabric bag as a donor compartment $(44 \pm 15 \mu \mathrm{m}$ pore size). The bag was immersed into a beaker (receptor compartment) containing $10 \mathrm{~mL}$ of double-distilled water as the release medium ( $\mathrm{pH}$ 6). The system was maintained for $3 \mathrm{~h}$ at $37^{\circ} \mathrm{C} \pm 0.5^{\circ} \mathrm{C}$ in a thermostatically controlled shaking water bath (Gallenkamp) at $50 \mathrm{rpm}$. Aliquots of $2 \mathrm{~mL}$ were withdrawn at intervals of $0.5,1,1.5,2$, and $3 \mathrm{~h}$, which were replaced by the same volume of fresh water (kept at the same temperature) to maintain constant volume. Samples were analyzed for AgNPs content spectrophotometrically at 
$\lambda_{\max } 420 \mathrm{~nm}$ against a blank sample that was similarly treated. Results were compared to the AgNPs dispersion of same concentration. All experiments were carried out in triplicates, and the average values were calculated. Kinetics of the AgNPs release data from the prepared hydrogels was analyzed, and details are provided in the Supplementary materials.

\section{Antibacterial activity using agar-well diffusion method}

In order to evaluate the release of the loaded AgNPs from the hydrogels (F1-F25) in the agar plates and their antibacterial activity, the prepared medicated formulations (200 $\mu \mathrm{g}$ of $500 \mu \mathrm{g}$ AgNPs $/ \mathrm{g}$ ) were loaded inside agar wells. Plates were incubated at $37^{\circ} \mathrm{C}$ for $24 \mathrm{~h}$, and then were examined for the diameters of the bacterial growth inhibition zone as previously described. Blank hydrogel formulations were also tested as positive control.

\section{In vivo studies}

Based on the previous in vitro studies and characterizations, $0.1 \% 10 \mathrm{mM}$ PEG-coated-AgNPs-loaded Na CMC hydrogel (F3) was selected for the in vivo studies. The in vivo studies involved the evaluation of wound-healing-promoting activity of AgNPs-loaded hydrogel as described previously. ${ }^{30}$ Then, in vivo antibacterial activity was evaluated, ${ }^{41}$ and the protocols were approved by the Assiut University Animal Ethical Committee. Ethical and legal approvals were obtained prior to the commencement of the study and all the animal experiments were approved by the Institutional Animal Ethical Committee of Faculty of Pharmacy, Assiut University, and it adheres to the Guide for the Care and Use of Laboratory Animals, 8th Edition, National Academies Press, Washington, DC, USA.

\section{In vivo wound-healing efficacy}

The wound-healing activity of the prepared $0.1 \% 10 \mathrm{mM}$ PEG-coated-AgNPs-loaded Na CMC hydrogel (selected formulation, F3) was investigated. Ten adult female rats aged 8-10 weeks and weighing 200-250 g were used. Animals were purchased from the Animal Facility of the Faculty of Medicine (Assiut University, Egypt). Rats were divided randomly into two groups $(\mathrm{n}=5)$. Group I served as test group which received $0.1 \%$ AgNPs hydrogel (F3), and group II served as a control and received the commercially available $1 \%$ silver sulfadiazine cream. Rats were kept in large cages and allowed food and water ad libitum. Rats were anesthetized using intraperitoneal (IP) thiopental injections, and were then shaved on their dorsal surfaces. A circular piece of full-thickness skin $\left(1 \times 1 \mathrm{~cm}^{2}\right)$ from each rat was excised using scissors, and wound was left undressed to the open environment. ${ }^{42}$ Treatment of both groups was started at the day of wound creation and lasted for $10 \mathrm{~d}$. Rate of healing in both groups, represented by percent wound contraction, was assessed and compared. Percent wound contraction was determined according to the following equation:

$\underset{\text { contraction }}{\% \text { wound }}=\frac{\text { Wound area day } 0-\text { Wound area day } n}{\text { Wound area day } 0} \times 100$

\section{In vivo antibacterial activity}

The antibacterial activity of $0.1 \% 10 \mathrm{mM}$ PEG-coatedAgNPs-loaded Na CMC hydrogel (selected formulation, F3) was evaluated using a superficial skin infection model ${ }^{41}$ using MRSA strain in animals and compared with that of $1 \%$ silver sulfadiazine cream, hydrogel blank formulation ( $3 \% \mathrm{Na}$ CMC blank hydrogel), and a group of animals with no treatment as a control group.

Twenty adult female mice were used in this study. All mice were 6-8 weeks old and weighing 20-25 g. Mice were purchased from the Animal Facility of the Faculty of Medicine (Assiut University, Egypt). Experimental study design is presented in Figure 1. Mice were housed in large cages (five animals per cage) and allowed food and water ad libitum. Four days and $1 \mathrm{~d}$ prior to the infection, mice were injected intraperitoneally with two doses of Endoxan ${ }^{\circledR} 200$ (cyclophosphamide). The first dose of cyclophosphamide was $150 \mathrm{mg} / \mathrm{kg}$ followed by a second dose of $100 \mathrm{mg} / \mathrm{kg}$. Cyclophosphamide was reported to reduce the mice peripheral blood neutrophils to $<100 / \mu \mathrm{L}$ blood, thus providing a susceptible environment for infection. ${ }^{41}$ Mice were anesthetized with IP thiopental injections, and then shaved on their dorsal surfaces. Skin wounds were created using the abrasion method which was applied on the dorsal surfaces of mice using 24-gauge needles. Crossed scratch lines $(6 \times 6)$ were created in a $1 \mathrm{~cm}^{2}$ area with damaged stratum corneum and upper layer of the epidermis, without affecting the dermis. Five minutes after wounding, an aliquot of MRSA suspension ( $100 \mu \mathrm{L}$ of $10^{8} \mathrm{CFU} / \mathrm{mL}$ in phosphate-buffered saline) was inoculated over each defined area containing the crossed scratches with a micropipette tip. Animals were divided into four groups each containing five animals and received the specified treatment $1 \mathrm{~d}$ postinfection according to each group $(0.5 \mathrm{~g} / \mathrm{d}$ for $15 \mathrm{~d})$. Group I was treated with the prepared $0.1 \%$ AgNPs gel formulation (F3), group II was treated with the commercially available $1 \%$ silver sulfadiazine cream, group III was treated with the blank hydrogel formulation (hydrogel 


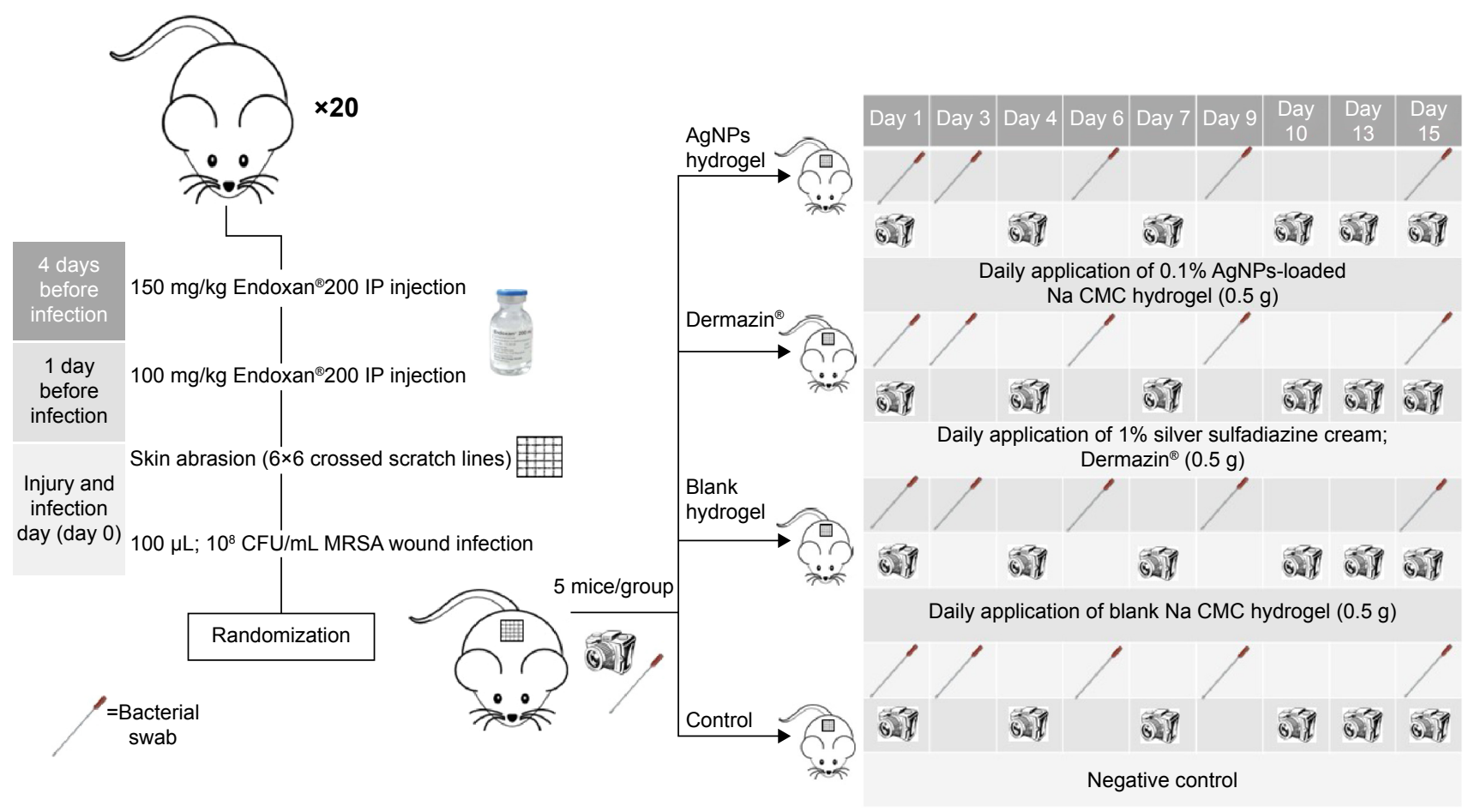

Figure I Graphical chart represents the design of the study on the in vivo antibacterial activity of AgNPs.

Abbreviations: AgNPs, silver nanoparticles; IP, intraperitoneal; CFU, colony-forming units; MRSA, methicillin-resistant Staphylococcus aureus; Na CMC, sodium carboxymethyl cellulose.

without AgNPs), and group IV was the control (without any application).

Swabs from the surface of the crossed scratches were taken using a sterilized cotton swab at $1 \mathrm{~d}$ (just before treatment), and at 3, 6, 9, and $15 \mathrm{~d}$ postinfection. MRSA $(\mathrm{CFU} / \mathrm{mL})$ were counted after serial dilution of the bacterial swab and cultured on a selective solid agar media (mannitol salt agar), and then incubated for $24 \mathrm{~h}$ at $37^{\circ} \mathrm{C}$.

\section{Histopathological examinations}

Light microscope examination using hematoxylin and eosin stain

To assess morphological alterations during the in vivo antibacterial activity study, the tissue samples from the mice back skin were harvested after euthanizing the mice and were processed routinely for light microscopic examination. Skin sections were evaluated for intercellular and intracellular epidermal edema, dermal edema, and inflammation. For the histological examinations by light microscope, small fresh pieces from the skin were taken from the four groups, fixed in $10 \%$ of neutral buffered formalin ( $\mathrm{pH} 7.2$ ), dehydrated in graded series of ethanol, cleared in methyl benzoate, and then embedded in paraffin wax. Thin paraffin sections $(5 \mu \mathrm{m})$ were prepared and stained with Harris's hematoxylin and eosin.

\section{Transition electron microscope examination}

To visualize the AgNPs diffusion from the hydrogel into the epidermal layers of the skin surface, TEM was used. Selected skin tissues were fixed in 2\% glutaraldehyde followed by osmium tetroxide and then dehydrated in ascending concentrations of ethanol. Samples were embedded in Epon 812 according to the protocol of the Electron Microscopy Unit (Assiut University, Egypt). Semi-thin $(1 \mu \mathrm{m})$ sections were cut on an Ultracut $\mathrm{E}$ ultramicrotome using a diamond knife, stained with toluidine blue, and examined by light microscope. Finally, ultrathin sections $(60 \mathrm{~nm})$ were cut with an ultramicrotome (Reichert Ultracuts), contrasted with an uranyl acetate and lead citrate, and examined with a transmission electron microscope (JEOL TEM 100 CXII) at $80 \mathrm{kV}$ and imaged. ${ }^{43}$

\section{Statistical analysis}

Statistical analysis was performed using SPSS statistical package. ${ }^{44}$ Basic statistical parameters (mean, standard deviation, or standard error) of the presented data were estimated. According to the number of the studied factors, results were subjected to one-, two-, and three-way analysis of variance (ANOVA) to study the simple and main effects between levels of the different factors (coating agents, gelling agents, and/or bacterial type). Test of homogeneity was carried out. 
Homogeneity of variance was evident in most cases and assumed in other cases. Tukey's post hoc test was carried out for each factor, and the homogenous subsets were identified at 0.05 level of significance.

\section{Results and discussion}

\section{Biosynthesis and characterization of AgNPs}

AgNPs were produced using a simple, fast, clean, benign, and ecofriendly alternative method to the complex chemical synthetic methods, where the crude fungal extract acts as reducing agent. ${ }^{45}$ Several groups have utilized the crude extract of fungi for myco-synthesis of AgNPs. ${ }^{31,46,47}$ Different studies have discussed the fabrication of AgNPs based on fungi-assisted bioreduction processes, as well as their antibacterial activities. ${ }^{20,48,49}$ The fungus Fusarium sp. can reduce aqueous silver ions extracellularly to generate AgNPs. ${ }^{46}$ The process of silver ions reduction occurs through the action of both reductase enzymes and electron shuttle quinones. ${ }^{47}$ In addition, biological nanoparticle synthesis often yields a more consistent size distribution pattern, as compared to other methods. In order to ensure the reproducibility of AgNPs yield and characteristics, synthetic conditions, such as duration, $\mathrm{pH}$, temperature, and $\mathrm{AgNO}_{3}$ starting concentration, were optimized. The optimal conditions for maximum AgNPs production were $\mathrm{pH} 7,1 \mathrm{mM}$ concentration of $\mathrm{AgNO}_{3}$, and $24 \mathrm{~h}$ incubation time.

The production of AgNPs in the solution was confirmed by visual detection of the color transformation from transparent to pale brown. The concentration of the synthesized AgNPs stock dispersion was measured using the AAS. XRD pattern of AgNPs synthesized using the fungus $F$. verticillioides extract is shown in Figure S1. The sharp peaks in the pattern indicate the existence of the silver and the crystalline nature of the biologically synthesized AgNPs. The four distinguished reflections at $38.1^{\circ}, 44.3^{\circ}, 64.5^{\circ}$, and $77.5^{\circ}$ in the XRD pattern are indexed to the (111), (200), (220), and (311) crystallographic planes of the face-centered cubic structure of silver, respectively (JCPDS file no 00-004-0783).

AgNPs were coated with PEG 6000, SDS, and $\beta-C D$ to improve the stability of the nanoparticles and reduce the growth of the particles via trapping of seeds and steric repulsion. Silver particles were characterized using different analytical techniques. UV-visible absorption spectra of the prepared AgNPs dispersions (before and after coating) were recorded in the range of 300-800 $\mathrm{nm}$ using a double-beam UV-visible spectrophotometer (Figure 2). Spectra of AgNPs dispersions exhibited a single SPR absorption band with a maximum of ca.

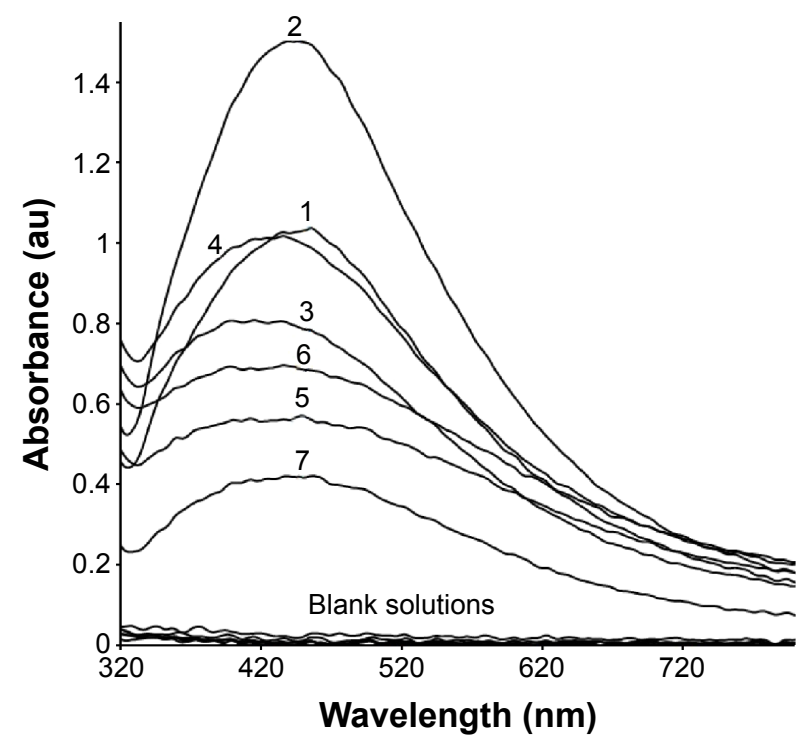

Figure 2 UV-visible spectrophotometric spectra of AgNPs dispersions: (I) $5 \mathrm{mM}$ PEG-coated AgNPs; (2) 10 mM PEG-coated AgNPs; (3) 5 mM SDS-coated AgNPs; (4) 10 mM SDS-coated AgNPs; (5) 5 mM $\beta$-CD-coated AgNPs; (6) $10 \mathrm{mM} \beta$-CDcoated $\mathrm{AgNPs}$; and (7) uncoated AgNPs and their solutions without AgNPs (blank solutions).

Abbreviations: AgNPs, silver nanoparticles; PEG, polyethylene glycol; SDS, sodium dodecyl sulfate; $\beta$-CD, $\beta$-cyclodextrin; UV, ultraviolet.

$420 \mathrm{~nm}$ that indicated the presence of spherical nanoparticles. ${ }^{16}$ Pal et a ${ }^{16}$ reported that the number of SPR peaks decreases as the symmetry of the nanoparticles increases, and they found that spherical AgNPs show only one peak, whereas disks and triangular nanoplates show two or more peaks. Coating of AgNPs using different materials led to an increase in the peak intensity. Furthermore, this peak intensity increase was directly proportional to the polymer concentration. PEG-coated AgNPs dispersions of 5 and $10 \mathrm{mM}$ concentrations showed a slight red shift to $450 \mathrm{~nm}$. SPR of metal nanoparticles absorption spectra is usually shifted to longer wavelengths when particle size increases. ${ }^{16}$ Size of AgNPs was determined using DLS and TEM imaging. The morphology of the particles was studied by TEM. Representative TEM micrographs of 5 mM PEG-, SDS-, and $\beta$-CD-coated and uncoated AgNPs are shown in Figure 3. Most of the nanoparticles were homogenous and spherical in shape, and the average particle size was $19.2 \pm 3.6,13 \pm 4,14 \pm 4.4$, and $15.7 \pm 4.8 \mathrm{~nm}$ for $5 \mathrm{mM}$ PEG-, SDS-, and $\beta$-CD-coated and uncoated $\mathrm{AgNPs}$, respectively $(\mathrm{n}=50$ ). Histograms (right-hand insets in the figures) indicate the AgNPs size distribution. There were no significant differences $(P>0.05)$ between the sizes of AgNPs measured using TEM. Therefore, DLS technique was exploited to measure the hydrodynamic size in water dispersions. Particle size measured using DLS was bigger than that obtained from TEM micrographs (Table 2) because DLS measures the hydrodynamic diameter of the particles. ${ }^{50}$ In addition, 
A

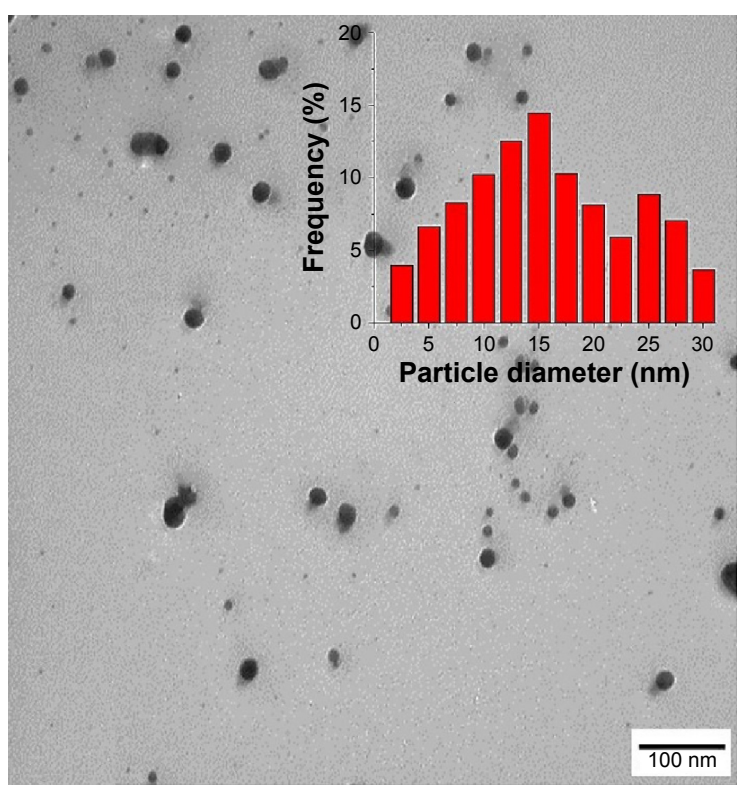

C

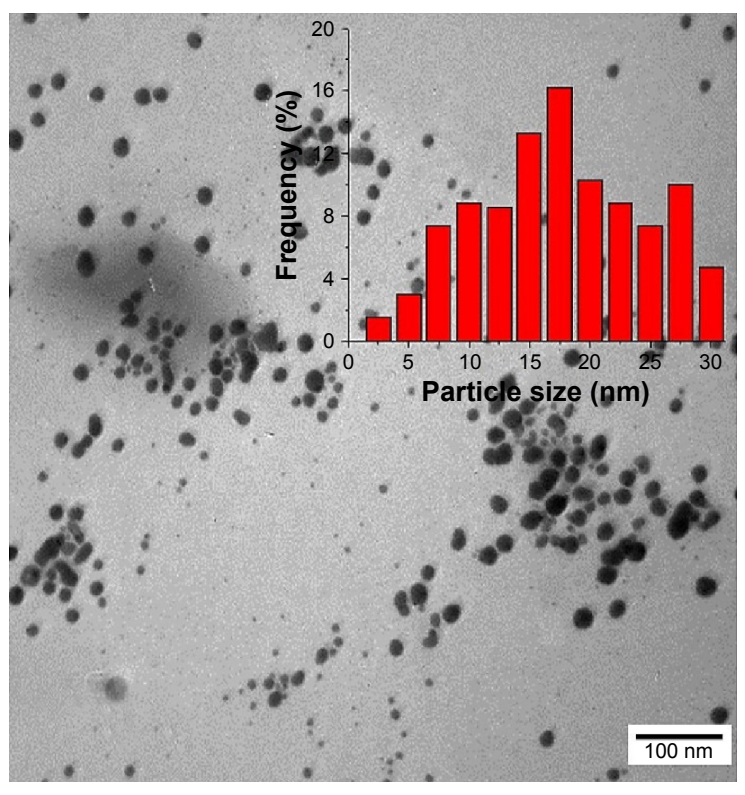

B

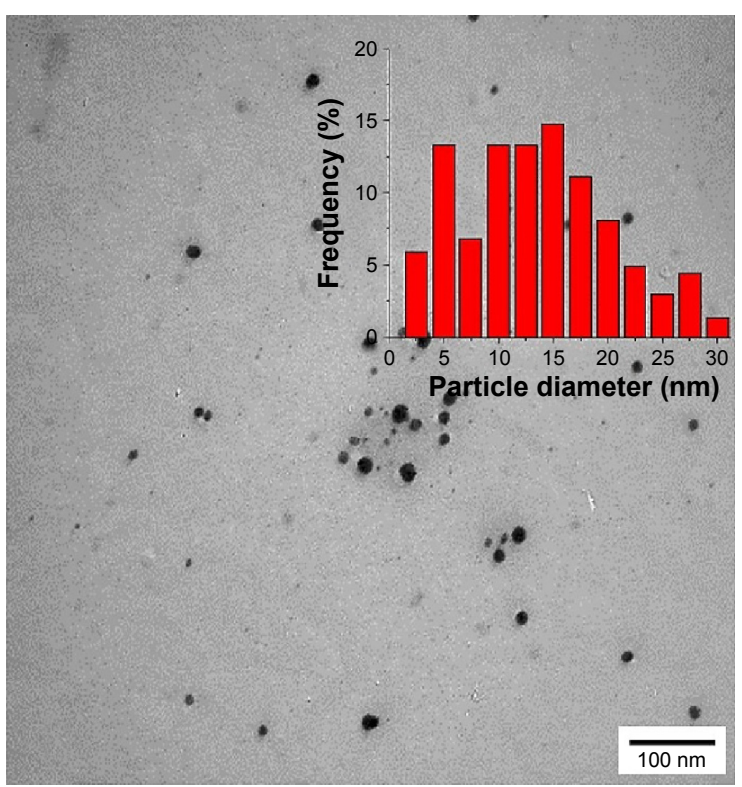

D

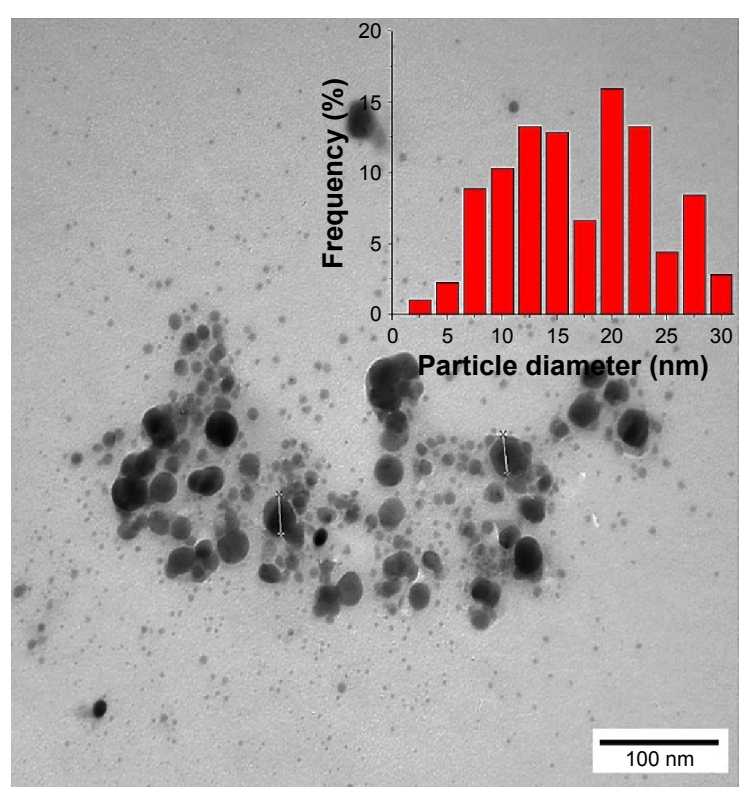

Figure 3 Representative TEM micrographs for the aqueous dried AgNPs (100 $\mu$ g AgNPs/mL): (A) uncoated AgNPs; (B) SDS-coated AgNPs; (C) PEG-coated AgNPs $(\times 100,000)$; (D) $\beta$-CD-coated AgNPs $(\times 140,000)$ with sizes $=15.7 \pm 4.8,13 \pm 4,19.2 \pm 3.6$, and I $4 \pm 4.4 \mathrm{~nm}$, respectively $(\mathrm{n}=50$, bar represents I00 $\mathrm{nm})$. Insets indicate histograms of AgNPs size distribution.

Abbreviations: TEM, transmission electron microscopy; AgNPs, silver nanoparticles; SDS, sodium dodecyl sulfate; PEG, polyethylene glycol; $\beta$-CD, $\beta$-cyclodextrin.

Table 2 Characterizations of the AgNPs dispersions in terms of size, PDI, and zeta-potential. Size was measured by using DLS and TEM

\begin{tabular}{|c|c|c|c|c|}
\hline AgNPs dispersion & $\begin{array}{l}\text { DLS: average particle } \\
\text { size } \pm \text { SD }(\mathrm{nm})\end{array}$ & $\begin{array}{l}\text { DLS: average } \\
\text { PDI } \pm \text { SD }\end{array}$ & $\begin{array}{l}\text { TEM: average particles } \\
\text { size } \pm \text { SD }(\mathbf{n m})\end{array}$ & $\begin{array}{l}\text { Zeta-potential } \pm \text { SD } \\
(\mathrm{mV})\end{array}$ \\
\hline 5 mM PEG-coated AgNPs & $54.2^{\mathrm{a}} \pm 8.1$ & $0.3 \pm 0.0$ & $19.2^{\mathrm{a}} \pm 3.6$ & $15.5^{\mathrm{a}} \pm 0.9$ \\
\hline 10 mM PEG-coated AgNPs & $77.7^{\mathrm{b}} \pm 11.0$ & $0.3 \pm 0.0$ & - & $11.9^{\mathrm{b}} \pm 0.6$ \\
\hline 5 mM SDS-coated AgNPs & $43.3^{\mathrm{a}} \pm 4.4$ & $0.5 \pm 0.1$ & $13.0^{\mathrm{a}} \pm 4.0$ & $25.3^{c} \pm 1.3$ \\
\hline 10 mM SDS-coated AgNPs & $57.2^{\mathrm{a}} \pm 10.0$ & $0.4 \pm 0.1$ & - & $28.2^{\mathrm{d}} \pm 0.9$ \\
\hline $5 \mathrm{mM} \beta$-CD-coated AgNPs & $86.4^{b} \pm 3.2$ & $0.4 \pm 0.0$ & $14.0^{\mathrm{a}} \pm 4.4$ & $17.8^{\mathrm{a}} \pm 1.1$ \\
\hline 10 mM $\beta$-CD-coated AgNPs & $86.3^{b} \pm 12.6$ & $0.3 \pm 0.0$ & - & $15.2^{\mathrm{a}} \pm 0.7$ \\
\hline Uncoated AgNPs & $48.5^{\mathrm{a}} \pm 14.3$ & $0.3 \pm 0.0$ & $15.7^{\mathrm{a}} \pm 4.8$ & $20.1^{a} \pm 1.5$ \\
\hline
\end{tabular}

Note: ${ }^{a-d}$ Refer to significant differences between different groups at the same column.

Abbreviations: AgNPs, silver nanoparticles; PDI, polydispersity index; DLS, dynamic light scattering; TEM, transmission electron microscopy; SD, standard deviation; PEG, polyethylene glycol; SDS, sodium dodecyl sulfate; $\beta-C D, \beta$-cyclodextrin. 
Ma et $\mathrm{al}^{51}$ have reported that the increased size obtained from DLS over TEM is due to the coating effect that decreased the particle diffusivity, thus resulting in a larger hydrodynamic size. DLS measurements of 5 and $10 \mathrm{mM}$ SDS-coated AgNPs and $5 \mathrm{mM}$ PEG-coated AgNPs were not significantly different $(P>0.05)$ from that of uncoated AgNPs; however, increasing the concentration of PEG from 5 to $10 \mathrm{mM}$ increased the hydrodynamic size significantly from 54.2 to $77.7 \mathrm{~nm}$. PDIs of all the AgNPs dispersions were $<0.5$, thus indicating a narrow and homogenous particle size distribution (Table 2)..$^{52,53}$ The surface charges of the synthesized AgNPs were determined by zeta-potential measurements (Table 2). Uncoated AgNPs showed a negative zeta-potential of $-20.1 \mathrm{mV}$ which was decreased upon coating with 5 and $10 \mathrm{mM}$ of neutral PEG to -15.5 and $-11.9 \mathrm{mV}$, respectively. Coating of the AgNPs with 5 and $10 \mathrm{mM}$ of the anionic surfactant SDS increased the negative charge significantly $(P<0.05)$ to -25.3 and $-28.2 \mathrm{mV}$, respectively. Sundararajan et $\mathrm{al}^{54}$ have reported that particles that possess zeta-potential values $>+30$ and $<-30 \mathrm{mV}$ are relatively stable. In the current study, AgNPs were stabilized by both electrostatic and steric repulsions.

\section{Effect of coating agent on the sedimentation rate of AgNPs in water}

The rates of sedimentation of the prepared dispersions of AgNPs were evaluated visually at $4^{\circ} \mathrm{C}$, and imaged at different time intervals for 1 year, and are shown in Figure 4. It is evident that $10 \mathrm{mM}$ PEG-coated AgNPs formed a stable dispersion without any particles aggregation and sedimentation for ca. 9 months, whereas lower concentration of the same polymer $(5 \mathrm{mM})$ afforded stability for ca. 3 months. On the contrary, sedimentation of uncoated, 5 and $10 \mathrm{mM}$ SDS-coated, and 5 and $10 \mathrm{mM} \beta$-CD-coated AgNPs from their colloidal dispersions was significant after the first month. Coating layers are reported to increase the stability of the particles by enhancing the electrostatic (as in the case of anionic SDS) or steric (as in the case of neutral PEG and $\beta-\mathrm{CD}$ ) repulsion. ${ }^{55} \mathrm{AgNPs}$ stabilized with steric repulsion (ie, PEG) are usually more stable than those stabilized via electrostatic repulsion (ie, SDS). ${ }^{55}$ Stiufiuc et al ${ }^{56}$ have demonstrated that coating AgNPs with PEG increased not only the steric distance between nanoparticles but also the hydrophilicity via hydrogen bonds formation with the solvent, thus preventing particles aggregation.

\section{MIC and MBC}

Table 3 summarizes the MIC and MBC values of the different AgNPs dispersions against both Gram-positive

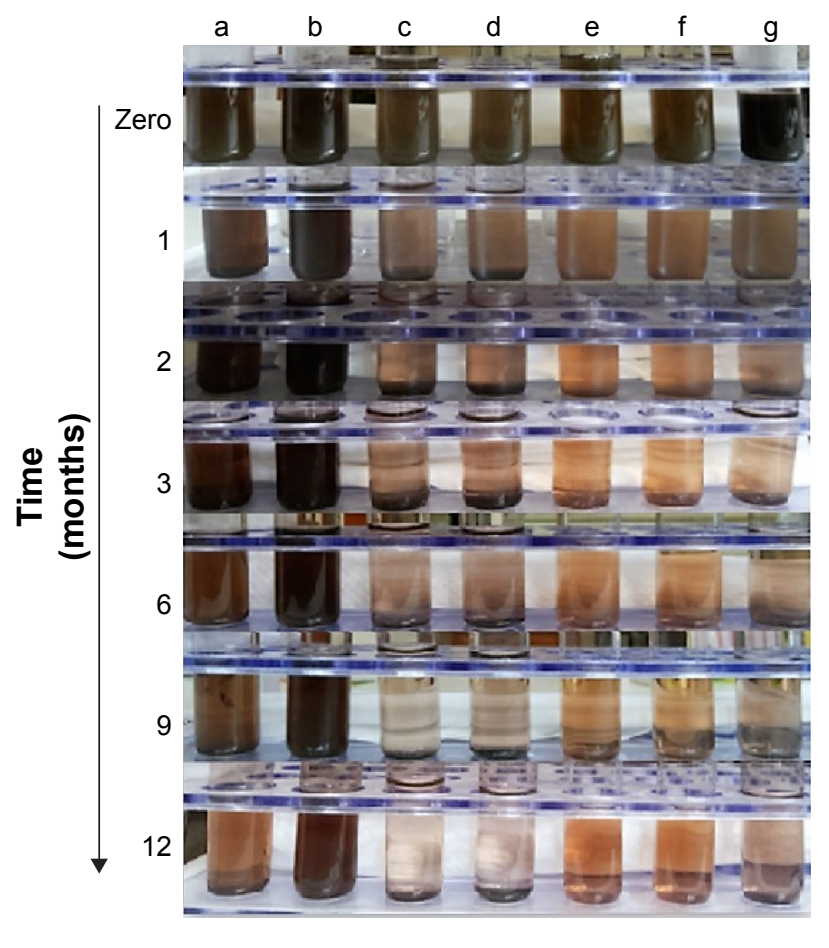

Figure 4 Effect of coating type on AgNPs ( $500 \mu \mathrm{ggNPs} / \mathrm{mL}$ ) sedimentation rate in water over time: (a) $5 \mathrm{mM}$ PEG-coated AgNPs; (b) $10 \mathrm{mM}$ PEG-coated AgNPs; (c) $5 \mathrm{mM}$ SDS-coated AgNPs; (d) $10 \mathrm{mM}$ SDS-coated AgNPs; (e) $5 \mathrm{mM} \beta$-CD-coated AgNPs; (f) $10 \mathrm{mM} \beta$-CD-coated AgNPs; and (g) uncoated AgNPs.

Abbreviations: AgNPs, silver nanoparticles; PEG, polyethylene glycol; SDS, sodium dodecyl sulfate; $\beta-C D, \beta$-cyclodextrin.

(MRSA and MSSA) and Gram-negative bacteria (E. coli). In the current study, MIC and MBC values of the studied AgNPs dispersions against MSSA, MRSA, and E. coli bacteria were in the range of $0.93-7.5$ and $3.7-15 \mu \mathrm{g} /$ $\mathrm{mL}$, respectively. The high antibacterial activity of the nanoparticles could be due to their small size (in the range of $13 \pm 4$ to $19.2 \pm 3.6 \mathrm{~nm}$ ), and subsequently large surface area of the particles. Several authors have reported that the antibacterial activity of AgNPs increases upon reduction of their particles size due to the increase in the surface area which allows greater contact with bacterial cells. ${ }^{57-59}$ Ansari et al ${ }^{57}$ studied the antibacterial activity of AgNPs $(5-10 \mathrm{~nm})$ against clinically isolated MSSA and MRSA, and reported that their MIC and MBC were in the range of $12.5-50$ and $12.5-100 \mu \mathrm{g} / \mathrm{mL}$, respectively. In the present work, the antibacterial activity of AgNPs dispersions was higher, which might be due to the difference in AgNPs synthetic method and the sources of the bacterial strains utilized in the two studies.

MIC and MBC values were subjected to two-way ANOVA without replicates to investigate the effects of coating agent and bacterial type in the study (Table 3). PEG, SDS, and $\beta-C D$ were studied previously as coating agents to 
Table 3 MIC and MBC of AgNPs dispersions against MSSA, MRSA, and Escherichia coli determined using microtiter plate method. Statistical data indicate the effect of bacterial type on the MIC/MBC of the prepared AgNPs, either uncoated or coated with various materials, regardless of the coating type

\begin{tabular}{|c|c|c|c|c|c|c|}
\hline \multirow{2}{*}{$\begin{array}{l}\text { Dispersion }(240 \mu \mathrm{g} \\
\text { AgNPs/mL) }\end{array}$} & \multicolumn{3}{|c|}{ MIC $(\mu \mathrm{g} / \mathrm{mL})$} & \multicolumn{3}{|c|}{ MBC $(\mu \mathrm{g} / \mathrm{mL})$} \\
\hline & MSSA & MRSA & E. coli & MSSA & MRSA & E. coli \\
\hline \multicolumn{7}{|l|}{ Dispersion $(240 \mu g$ AgNPs/mL) } \\
\hline 5 mM PEG-coated AgNPs & 1.87 & 3.75 & 7.50 & 7.50 & 7.50 & 15.00 \\
\hline 10 mM PEG-coated AgNPs & 1.87 & 3.75 & 7.50 & 7.50 & 7.50 & 15.00 \\
\hline 5 mM SDS-coated AgNPs & 0.93 & 1.87 & 7.50 & 3.75 & 3.75 & 7.50 \\
\hline 10 mM SDS-coated AgNPs & 1.87 & 3.75 & 3.75 & 7.50 & 7.50 & 3.75 \\
\hline $5 \mathrm{mM} \beta$-CD-coated AgNPs & 1.87 & 3.75 & 7.50 & 3.75 & 3.75 & 7.50 \\
\hline $10 \mathrm{mM} \beta-\mathrm{CD}$-coated AgNPs & 1.87 & 3.75 & 7.50 & 7.50 & 3.75 & 7.50 \\
\hline Uncoated AgNPs & 1.87 & 3.75 & 7.50 & 7.50 & 7.50 & 15.00 \\
\hline Main effects of bacteria \pm SD & $1.70^{\mathrm{a}} \pm 0.35$ & $3.80^{\mathrm{b}} \pm 0.35$ & $6.90^{c} \pm 0.35$ & $6.40^{\mathrm{a}} \pm 0.93$ & $5.80^{\mathrm{a}} \pm 0.93$ & $10.20^{\mathrm{b}} \pm 0.94$ \\
\hline
\end{tabular}

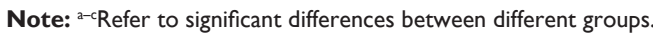

Abbreviations: MIC, minimum inhibitory concentration; MBC, minimum bactericidal concentration; AgNPs, silver nanoparticles; MSSA, methicillin-sensitive Staphylococcus aureus; MRSA, methicillin-resistant $S$. aureus; PEG, polyethylene glycol; SDS, sodium dodecyl sulfate; $\beta$-CD, $\beta$-cyclodextrin; SD, standard deviation.

enhance the antibacterial activity of AgNPs, as compared to the naked nanoparticles. ${ }^{10,19}$ In the present work, the effect of two different concentrations (5 and $10 \mathrm{mM}$ ) of PEG, SDS, and $\beta-C D$ as coating agents on the antibacterial activity of AgNPs was studied. Neither the change in the type of coating nor the concentration of the coating materials had significant effect on the MIC and MBC values of AgNPs ( $P=0.0468$ and $P=0.061$, respectively).

Bacterial types included Gram-negative bacteria represented by $E$. coli and Gram-positive bacteria represented by two strains, MRSA and MSSA. MIC and MBC values of different $\mathrm{AgNPs}$ dispersions against $E$. coli were significantly higher than those against MRSA and MSSA $(P<0.0001$ and $P<0.01$, respectively). Also, the effect of AgNPs dispersions against sensitive (MSSA) and resistant (MRSA)
Gram-positive bacteria was studied. MIC values of AgNPs dispersions against MRSA showed twofold significant increase than those against MSSA $(P>0.0001)$. However, MBC values against both MRSA and MSSA showed no significant difference, which indicates that AgNPs activity was not affected by the different resistance mechanisms exerted by MRSA. ${ }^{8}$

The effect of AgNPs dispersions on the bacterial growth was confirmed using agar-well diffusion method (Table 4). Results indicated that the effects of coating agents and bacterial type on the measured inhibition zones were similar to those obtained from MIC and MBC measurements. MSSA and MRSA were significantly $(P<0.01)$ more sensitive to the antibacterial effect of the AgNPs dispersions than E. coli which exhibited the lowest

Table 4 Determination of inhibition zones for different AgNPs dispersions against MSSA, MRSA, and Escherichia coli using agar-well diffusion method. Statistical data indicate the main effects of bacterial type on the inhibition zones, regardless of the coating type, and the main effects of coating agents, regardless of the bacterial type

\begin{tabular}{|c|c|c|c|c|}
\hline \multirow{2}{*}{$\begin{array}{l}\text { Dispersion }(240 \mu \mathrm{g} \\
\text { AgNPs/mL; } 200 \mu \mathrm{L})\end{array}$} & \multicolumn{3}{|c|}{ Zone of inhibition \pm SD $(\mathrm{mm})(\mathrm{n}=3)$} & \multirow{2}{*}{$\begin{array}{l}\text { Main effects of } \\
\text { coating } \pm \text { SD }(\mathrm{mM})\end{array}$} \\
\hline & MSSA & MRSA & E. coli & \\
\hline \multicolumn{5}{|l|}{ Dispersion $(240 \mu \mathrm{g}$ AgNPs/mL; $200 \mu \mathrm{L})$} \\
\hline 5 mM PEG-coated AgNPs & $22.0^{a} \pm 0.5$ & $21.0^{\mathrm{a}} \pm 0.5$ & $16.0^{\mathrm{b}} \pm 0.0$ & $19.7^{A} \pm 0.2$ \\
\hline 10 mM PEG-coated AgNPs & $23.0^{\mathrm{a}} \pm 0.5$ & $22.0^{\mathrm{a}} \pm 0.0$ & $16.0^{\mathrm{b}} \pm 0.0$ & $20.2^{A} \pm 0.2$ \\
\hline 5 mM SDS-coated AgNPs & $25.0^{a} \pm 0.5$ & $23.0^{\mathrm{b}} \pm 0.0$ & $18.0^{\circ} \pm 0.5$ & $21.7^{\mathrm{B}} \pm 0.2$ \\
\hline 10 mM SDS-coated AgNPs & $25.0^{\mathrm{a}} \pm 0.0$ & $24.0^{\mathrm{a}} \pm 0.0$ & $19.0^{b} \pm 1.5$ & $22.5^{\complement} \pm 0.2$ \\
\hline $5 \mathrm{mM} \beta-\mathrm{CD}$-coated AgNPs & $23.0^{\mathrm{a}} \pm 0.5$ & $21.0^{\mathrm{b}} \pm 0.0$ & $17.0^{\circ} \pm 1.0$ & $20.2^{\mathrm{A}} \pm 0.2$ \\
\hline $10 \mathrm{mM} \beta-\mathrm{CD}$-coated AgNPs & $23.0^{\circ} \pm 0.5$ & $22.0^{\circ} \pm 0.0$ & $17.0^{\mathrm{b}} \pm 0.0$ & $20.3^{A} \pm 0.2$ \\
\hline Uncoated AgNPs & $22.0^{\mathrm{a}} \pm 0.5$ & $21.0^{\mathrm{a}} \pm 0.5$ & $16.0^{\mathrm{b}} \pm 0.0$ & $19.7^{A} \pm 0.2$ \\
\hline Main effects of bacteria $\pm S D(m M)$ & $22.8^{\mathrm{a}} \pm 0.1$ & $22 . I^{a} \pm 0.1$ & $16.7^{b} \pm 0.1$ & \\
\hline
\end{tabular}

Notes: ${ }^{a-c}$ Refer to significant differences at the same row (between bacterial types). ${ }^{A-C}$ Refer to significant differences at the same column (between coating agents). Abbreviations: AgNPs, silver nanoparticles; MSSA, methicillin-sensitive Staphylococcus aureus; MRSA, methicillin-resistant S. aureus; SD, standard deviation; PEG, polyethylene glycol; SDS, sodium dodecyl sulfate; $\beta$-CD, $\beta$-cyclodextrin. 
inhibition zone. The sensitivity of both MSSA and MRSA to AgNPs dispersions was similar $(P>0.01)$, except in the case of $5 \mathrm{mM}$ SDS-coated AgNPs and $5 \mathrm{mM} \beta$-CD-coated AgNPs. Regarding the coating materials, there were no significant differences in the antibacterial activity of AgNPs dispersions $(P>0.01)$, except for 5 and $10 \mathrm{mM}$ SDS-coated AgNPs. SDS-coated AgNPs exerted a slightly enhanced activity, which might be due to SDS ability to disrupt bacterial cell wall and increase its permeability. ${ }^{19}$ Some studies reported a higher sensitivity for $E$. coli than S. aureus toward AgNPs. ${ }^{23,60,61}$ This was explained by the different characteristics of Gram-positive and Gramnegative bacteria in the membrane structure particularly in the thickness of the peptidoglycan layer. ${ }^{59}$ However, several authors reported that the antibacterial activity of AgNPs dispersions is more pronounced in case of MSSA and MRSA, as compared to E. coli. ${ }^{10,20,62,63}$ Therefore, the bacterial membrane structure is not the only factor that affects the antibacterial activity of nanoparticles, but also the sources of the bacterial strains.

\section{Evaluation of AgNPs-loaded hydrogels}

The formulated AgNPs hydrogels (F1-F25) were homogenous with brownish color due to the presence of AgNPs, while the blank hydrogels were transparent. Formulation F24 (5 mM SDS-coated AgNPs loaded in 3\% [w/w] chitosan hydrogel) precipitated immediately after preparation, which could be due to interaction between the anionic surfactant SDS and the positively charged chitosan polymer (gelling agent). Hence, this formulation was excluded from further characterizations and studies.

In order to study the flow behavior of the formulations, viscosity values were plotted against spindle speeds (rpm) and examined for the shape of the generated rheograms. It was noticed from the rheograms (Figure S2) that all the prepared AgNPs-loaded hydrogel formulations showed a pseudoplastic behavior (shear thinning behavior). Hydrogels with shear thinning behavior flow constantly under shear stress and recover quickly after stress removal. ${ }^{64}$ This behavior is prerequisite for gel formulations intended for topical applications to fulfill the filling and application requirements. ${ }^{65}$ Although incorporation of AgNPs within the polymer network of the prepared hydrogels did not affect flow behavior, it decreased viscosity when compared to the blank hydrogels (data not shown). Generally, uncoated AgNPs-loaded hydrogels exhibited the highest viscosity followed by those loaded with PEG-coated AgNPs. AgNPsloaded hydrogels formulated using chitosan and Pluronic
F-127 as gelling agents exhibited the highest viscosity, while those prepared using HPMC showed the lowest viscosity. Similar to the viscosity study, hydrogels with low viscosity showed high spreadability (data not shown).

Release studies showed that hydrogel formulations exhibited AgNPs release (30\%-90\%) when compared to AgNPs dispersion (100\%) after $3 \mathrm{~h}$. All the prepared hydrogels released AgNPs at a concentration $(\geq 10 \mu \mathrm{g}$ AgNPs after $30 \mathrm{~min}$ ) that exceeded their MIC against MSSA, MRSA, and E. coli $(0.93-7.5 \mu \mathrm{g} / \mathrm{mL})$. AgNPs-loaded hydrogels could be used as promising topical antibacterial formulations that allow rapid release of AgNPs, and hence, rapid antibacterial effect at the infection sites before disease progression or gel clearance occurs.

Time-dependent in vitro release of AgNPs over $3 \mathrm{~h}$ from all the studied hydrogel formulations is shown in Figure S3. Differences in the release of AgNPs from the prepared hydrogel formulations after $1.5 \mathrm{~h}$ were evaluated using two-way ANOVA to study the effect of coating agent and gelling polymer (Table $\mathrm{S} 1)$. $\mathrm{Na} \mathrm{CMC,} \mathrm{Na}$ alginate, and chitosan hydrogels loaded with $5 \mathrm{mM} \beta$-CD-coated AgNPs exhibited the lowest release rate, which might be due to the crosslinking that occurred between cyclodextrin and the polymer matrices which retarded AgNPs release. Bibby et al ${ }^{66}$ reported a crosslinking between $\mathrm{CD}$ and polymeric formulations which resulted in a decrease in the polymer mesh size, thus decreasing drug release. Izawa et $a{ }^{67}$ designed a unique system for controlled release of ondansetron which was composed of $\beta-C D$ crosslinked with alginate as the main chain polymer. Many authors reported the advantages of using $\beta-C D$ and chitosan together in controlling drug release from polymeric matrices. ${ }^{68,69}$ Regarding other coating agents, the release from hydrogel formulations was in the following descending order: $10 \mathrm{mM}$ PEG-, $5 \mathrm{mM}$ PEG-, and 5 mM SDS-coated-AgNPs-loaded and uncoated AgNPsloaded formulations. The resulted release patterns of $10 \mathrm{mM}$ PEG-coated-AgNPs-loaded hydrogel might be attributed to its low viscosity, whereas the higher viscosity exhibited by uncoated AgNPs-loaded hydrogels resulted in a slower release pattern. Analysis of the kinetics of the in vitro release of AgNPs demonstrated that the release kinetics of AgNPs from most of the hydrogel formulations was best fitted to Higuchi diffusion model. Further details are provided in the Supplementary materials (Table S2).

\section{Antibacterial activity of hydrogels}

Agar-well diffusion method was used to evaluate the release of AgNPs in the agar plates and their subsequent 


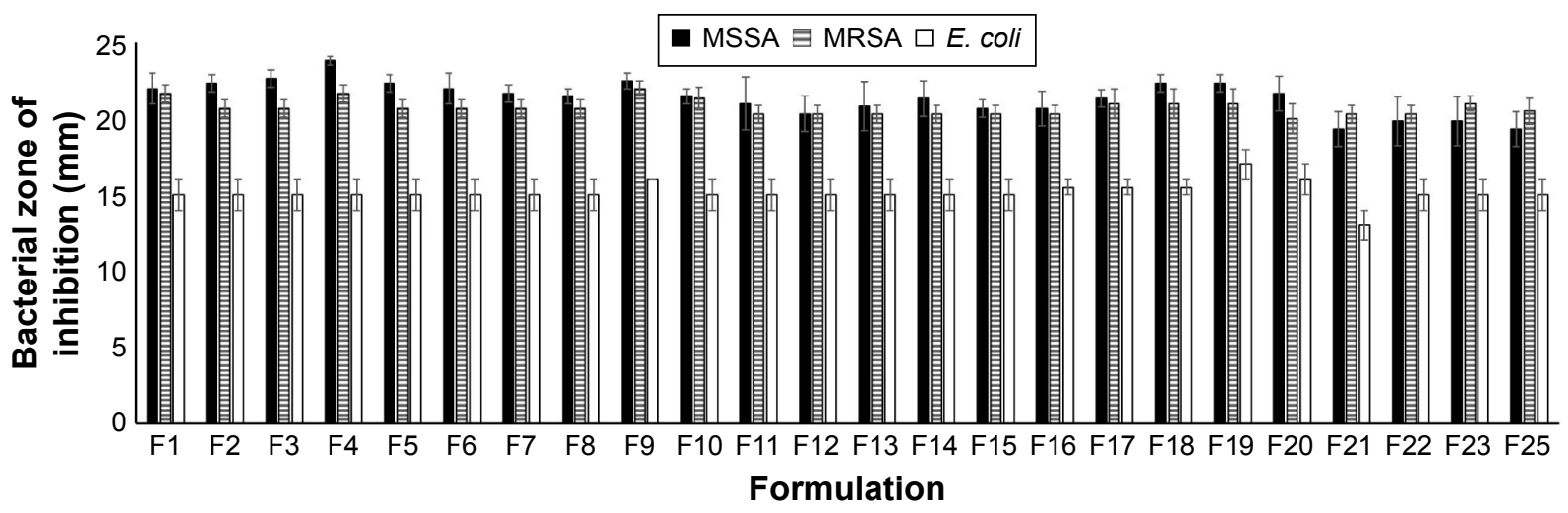

Figure 5 Bacterial inhibition zones of AgNPs-loaded hydrogels against MSSA, MRSA, and Escherichia coli using agar-well diffusion method, where FI-F5, F6-FI0, FII-FI5, FI6-F20, and F2I-F25 are Na CMC, Na alginate, HPMC, Pluronic F-127, and chitosan hydrogels loaded with AgNPs, respectively.

Abbreviations: AgNPs, silver nanoparticles; MSSA, methicillin-sensitive Staphylococcus aureus; MRSA, methicillin-resistant S. aureus; Na CMC, sodium carboxymethyl cellulose; $\mathrm{Na}$ alginate, sodium alginate; HPMC, hydroxypropylmethyl cellulose.

antimicrobial activity and zones of bacterial growth inhibition (Figure 5). All the tested formulations demonstrated antibacterial activities. The bacterial inhibition zone data were analyzed by factorial ANOVA, to study the main effects of gelling polymers, coating agents, and bacterial type. No zone of inhibition was obtained with the control gel formulations (without AgNPs). Gelling agents included five levels ( $\mathrm{Na}$ CMC, Na alginate, HPMC, Pluronic F-127, and chitosan), and coating agents also had five levels (no-coat, $5 \mathrm{mM}$ PEG 6000, $10 \mathrm{mM}$ PEG 6000, $5 \mathrm{mM}$ SDS, and $5 \mathrm{mM} \beta-\mathrm{CD}$ ), while bacteria comprised three levels (MSSA, MRSA, and E. coli). Similar to what has been observed in the antibacterial activity study of AgNPs dispersions, AgNPs with different coating agents showed similar $(P>0.001)$ effect on the bacterial growth inhibition zone with all the studied gelling agents except for $\mathrm{Na}$ alginate gel and Pluronic F-127 gel, where using $5 \mathrm{mM}$ SDS-coated AgNPs showed an increase in the bacterial growth inhibition zones. Formulations with different gelling agents showed significant differences in the bacterial growth inhibition zones where the zones of inhibition for the $\mathrm{Na} \mathrm{CMC}, \mathrm{Na}$ alginate, and Pluronic F-127 gelling agents were significantly $(P<0.001)$ wider than those of HPMC and chitosan. Regarding the bacterial type, all the formulations showed significant differences in the bacterial growth inhibition zones between $E$. coli and both MSSA and MRSA, where the latter two bacteria demonstrated higher sensitivity to the AgNPs-loaded hydrogels. These results were similar to those obtained from the determination of MIC and MBC, and agar-well diffusion methods for the AgNPs dispersions (vide supra). In conclusion, the most evident effect on the bacterial growth inhibition zones was for the bacterial type, followed by the gelling agent and the coating type.

\section{In vivo studies}

From the previous in vitro studies and characteristics of the prepared formulations, it was noticed that, although SDScoated AgNPs showed a slight increase in the antibacterial activity in the agar-well diffusion study, $10 \mathrm{mM}$ PEG-coated AgNPs dispersion was preferred. The use of PEG as a coating agent resulted in a stable dispersion without any particles aggregation or sedimentation for at least 9 months. PEGcoated-AgNPs-loaded hydrogel also showed faster release of the loaded AgNPs from the hydrogels. Hydrogels prepared using $10 \mathrm{mM}$ PEG as the coating agent and $3 \% \mathrm{Na} \mathrm{CMC}$ as the gelling agent had the most reasonable viscosity values among the tested AgNPs-loaded hydrogels, in addition to an intermediate spreadability and good consistency. Hence, formulation (F3) that contains $10 \mathrm{mM}$ PEG and $3 \%(\mathrm{w} / \mathrm{w}) \mathrm{Na}$ $\mathrm{CMC}$ was selected for the further animal studies to investigate the in vivo efficacy of AgNPs. First, the wound-healing efficacy and prevention of initial growth of any bacteria at wound sites were studied. Second, the efficacy against MRSA-infected wound model was investigated.

\section{Wound healing}

Dermal wound healing is a complicated process that involves proper harmony between several skin components to allow for the repair of the damaged tissues and to restore the normal skin functions. ${ }^{70}$ The use of a broad-spectrum antibacterial agent (eg, AgNPs) that provides a septic environment might aid in the effective wound repair. Liu et al ${ }^{71}$ highlighted the role of AgNPs in wound-healing process and demonstrated that AgNPs could enhance reepitheilalization and wound contraction process. Ten adult female rats were used and divided randomly into two groups $(\mathrm{n}=5)$. After skin excision, the wound was left undressed to the open environment. 


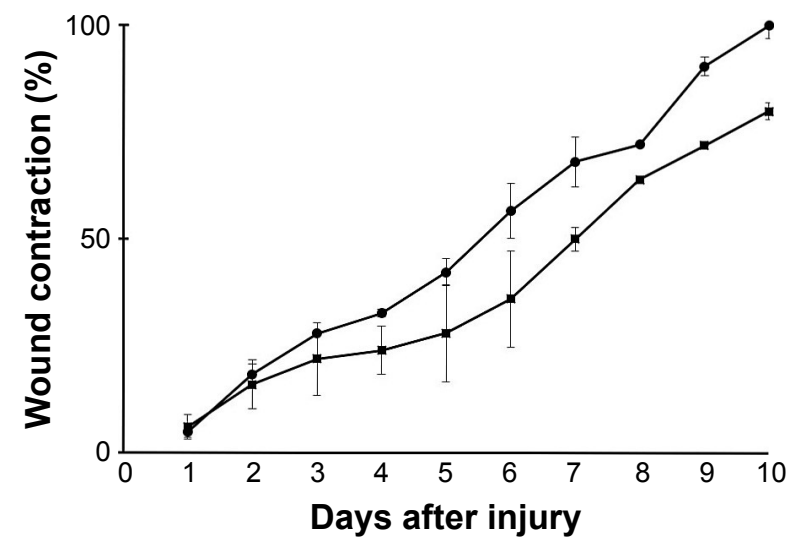

Figure 6 Percent of wound contraction in rats during the $10 \mathrm{~d}$ of treatment. Hydrogel loaded with $0.1 \%$ AgNPs (circles) was compared to I\% silver sulfadiazine cream (squares).

Abbreviation: AgNPs, silver nanoparticles.

Group I received $0.1 \%$ AgNPs hydrogel (F3), and group II received the commercially available $1 \%$ silver sulfadiazine cream. Treatment of both groups was started at the day of wound creation and lasted for $10 \mathrm{~d}$. Group I exhibited faster wound closure as compared to group II that received the commercially available cream, as demonstrated by the higher percentage of wound contraction during the experiment as compared to the values measured for the commercial silver sulfadiazine cream (Figure 6). Similar observations were obtained by Tian et $\mathrm{al}^{142}$ who investigated the woundhealing efficacy of AgNPs-coated dressing in different diabetic and nondiabetic animal wound models. Rapid wound healing with better scar appearance and normal hair growth in the AgNPs-treated group, as compared to silver sulfadiazinetreated group, was observed. Franková et $\mathrm{al}^{72}$ have studied the in vitro effect of AgNPs as wound-healing promoters. They have reported that AgNPs decreased the release of some pro-inflammatory cytokines and growth factors from normal human epidermal keratinocytes (NHEKs) and normal human dermal fibroblasts after $24 \mathrm{~h}$ at all the studied AgNPs concentrations $(0.25,2.5$, and $25 \mu \mathrm{g} / \mathrm{mL})$. Other authors studied the effect of different concentrations of polyvinylpyrrolidonecoated AgNPs on NHEKs and reported that AgNPs decreased the keratinocytes viability, metabolism and proliferation, and their migratory potential. ${ }^{73}$ However, they mentioned that the effect might be different in vivo as keratinocytes are surrounded by other types of cells that protect them against harmful stimuli. In our in vivo wound-healing study, $0.1 \%$ AgNPs-loaded hydrogel promoted wound healing more than the commercially available $1 \%$ silver sulfadiazine.

\section{In vivo antibacterial activity}

Skin cuts and abrasions are susceptible to infections, and it is important to rapidly eradicate the bacteria from the infectious lesions to allow for rapid wound healing and to reduce the morbidity rate. ${ }^{74}$ MRSA is the main cause of worldwide nosocomial infections and usually causes superficial lesions in human skin, localized abscesses, septicemia, pneumonia, and bacteremia. ${ }^{8}$ The antibacterial activity of the biologically synthesized $0.1 \% 10 \mathrm{mM}$ PEG-coated-AgNPs-loaded $\mathrm{Na}$ CMC hydrogel (F3) against MRSA-infected skin model was tested in mice. Dai et $\mathrm{al}^{41}$ reported that this experimental model produces a chronic and stable wound infection which might develop a severe morbidity or mortality in mice. All the studied groups were observed, and representative mice skin abrasion wounds were imaged daily at different time intervals (Figure 7). The group treated with AgNPs-loaded hydrogel (F3) showed more efficient healing of the infected abrasion as compared to the group treated with the silver sulfadiazine cream. No healing was observed in the infected wounds of the untreated and blank hydrogel-treated mice groups, in addition to oozing of pus at the infected sites. Wound swabs from each group were taken at different time intervals and cultured on a selective agar media to measure the growth of the microorganisms. The average bacterial count in the mice groups before beginning of the treatment $(1 \mathrm{~d})$ was ca. $5 \times 10^{5}$ $\mathrm{CFU} / \mathrm{mL}$. The percentages of bacterial count (as compared to the control untreated group) in the mice skin infected abrasions $(n=5)$ at different time intervals after daily application of the topical treatments were calculated and are presented in Figure 8. The mice group treated with $0.1 \%$ AgNPs hydrogel $(\mathrm{F} 3)$ exhibited a significantly $(P<0.05)$ faster and superior bacterial growth reduction when compared to the other groups during the $15 \mathrm{~d}$ of the treatment. AgNPs hydrogel-treated skin exhibited $20.5 \%$ of the bacterial count in the control untreated skin versus $44.7 \%$ and $94.5 \%$ for the silver sulfadiazine cream- and blank hydrogel-treated groups, respectively, in the first bacterial swab analysis after beginning of the treatment ( $3 \mathrm{~d}$ ). In the last bacterial swab analysis (15 d), AgNPs hydrogel-treated skin exhibited 2.7\% of the bacterial count in the control untreated skin, whereas silver sulfadiazine cream- and the blank hydrogel-treated groups exhibited $30 \%$ and $100 \%$ of the bacterial count, respectively, as compared to the previous bacterial swab analysis ( $9 \mathrm{~d})$. The observed increase of bacterial count measured at $15 \mathrm{~d}$ compared to $9 \mathrm{~d}$ in the silver sulfadiazine cream-treated mice group (Figure 8 ) was not significant $(P>0.05)$. In addition, the bacterial count in the blank hydrogel-treated mice group decreased insignificantly over time $(P>0.05)$ when compared to the $0.1 \%$ AgNPs hydrogel-treated group and $1 \%$ silver sulfadiazine cream-treated group. This might be due to the normal recovery of their immune systems over time after initial suppression using cyclophosphamide. 


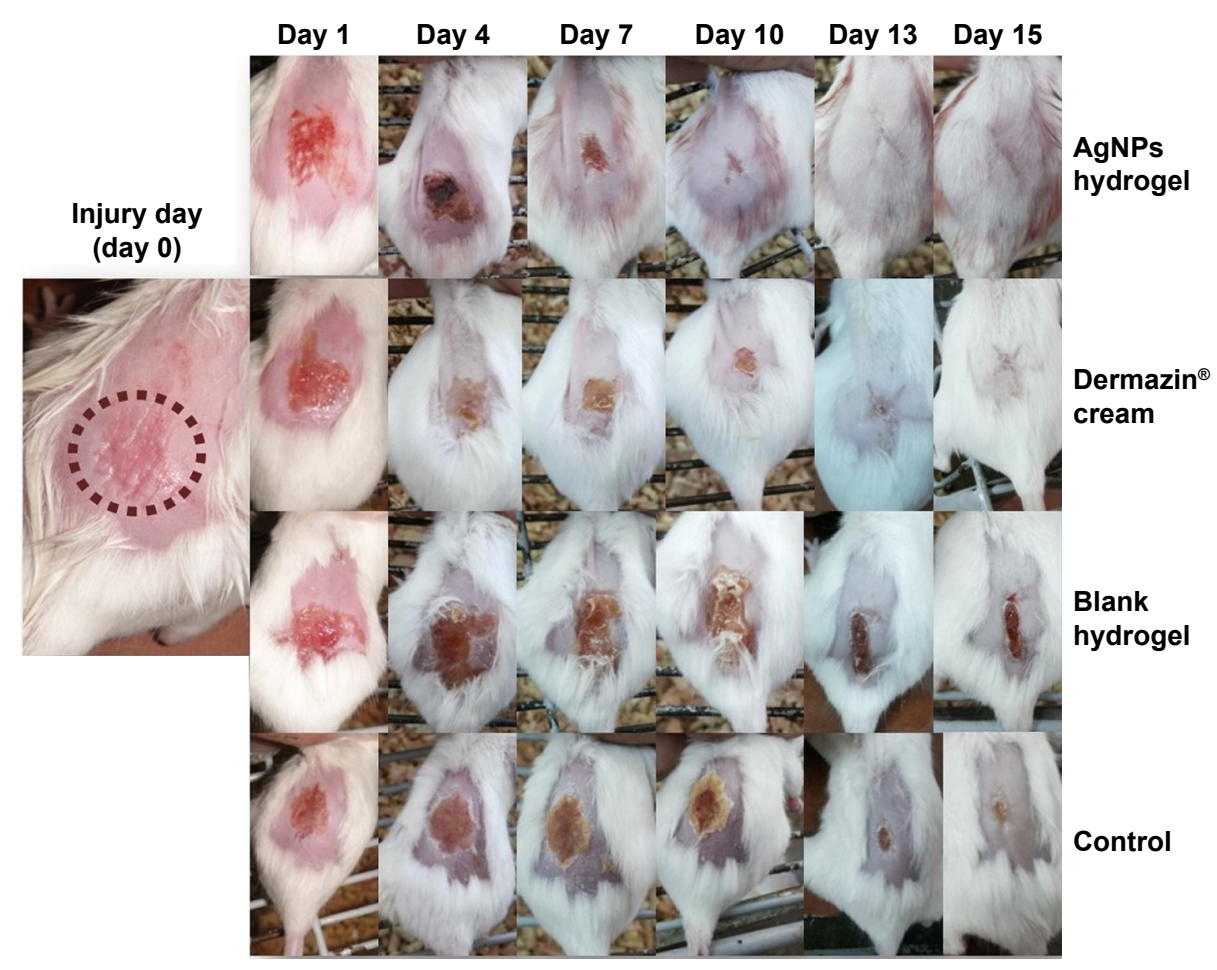

Figure 7 Successive images of representative mice skin abrasion wounds infected with MRSA at different time intervals. Two groups were treated with $0.1 \%$ AgNPs hydrogel and $\mathrm{I} \%$ silver sulfadiazine cream. The two other groups were the blank hydrogel-treated group and control untreated mice. Abbreviations: MRSA, methicillin-resistant Staphylococcus aureus; AgNPs, silver nanoparticles.

Mortality and morbidity of animals were observed during the experiment in the different studied groups (Table 5). No weight loss and suppuration or death were observed in mice treated with the AgNPs hydrogel with normal hair growth, whereas the silver sulfadiazine cream-treated group showed $20 \%$ weight loss and $20 \%$ mortality. Similar results were obtained by Hendi ${ }^{75}$ who reported that AgNPstreated group showed the most resemblance to normal skin with thin epidermis and nearly normal hair follicles.

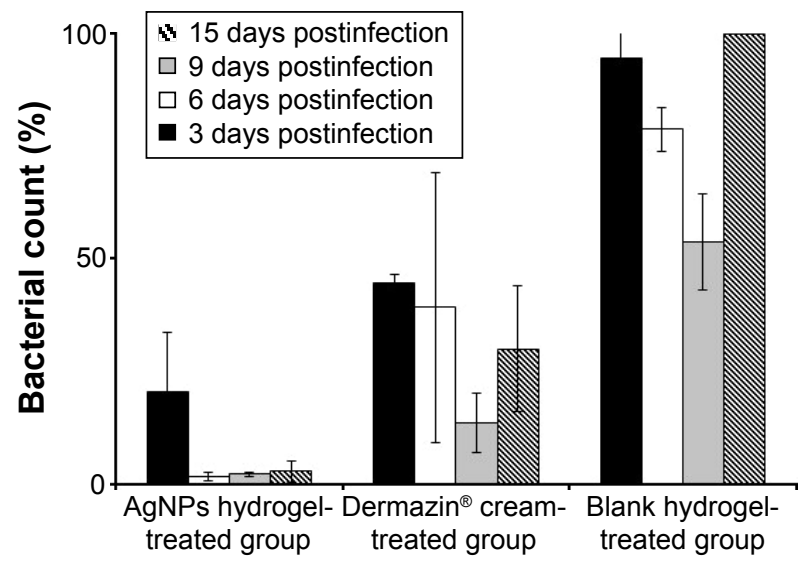

Figure 8 Bacterial count in the infected abrasion wounds of different mice groups at different time intervals expressed as percentages of the bacterial counts in the control untreated mice group. The studied groups are $0.1 \% \mathrm{AgNPs}$ hydrogel-treated group, $1 \%$ silver sulfadiazine cream-treated group, and blank hydrogel-treated group. Abbreviation: AgNPs, silver nanoparticles.
Blank hydrogel-treated mice and untreated mice showed 50\% weight loss and $60 \%-80 \%$ suppuration at the end of the treatment course. Proliferation of MRSA at the injury sites in the latter two mice groups resulted in the observed inflammation, pus formation, and disrupted wound-healing process.

\section{Histopathological studies}

Light microscopic examination of the skin samples after staining with hematoxylin and eosin showed great histological differences between the four groups. Skin samples from the $0.1 \%$ AgNPs hydrogel-treated group showed a well-stratified

Table 5 Mortality and morbidity observed at the end of the study in the MRSA-infected mice groups

\begin{tabular}{|c|c|c|c|c|}
\hline \multirow[t]{2}{*}{ Observation } & \multicolumn{4}{|c|}{ Percentage of animals $(n=5)$} \\
\hline & $\begin{array}{l}\text { AgNPs } \\
\text { hydrogel }\end{array}$ & $\begin{array}{l}\text { silver sulfadiazine } \\
\text { cream }\end{array}$ & $\begin{array}{l}\text { Blank } \\
\text { hydrogel }\end{array}$ & $\begin{array}{l}\text { Untreated } \\
\text { mice }\end{array}$ \\
\hline \multicolumn{5}{|l|}{ Morbidity* } \\
\hline Suppuration & $0 \%$ & $0 \%$ & $80 \%$ & $60 \%$ \\
\hline Weight loss & $0 \%$ & $20 \%$ & $50 \%$ & $50 \%$ \\
\hline Hair growth & Normal & Normal & Retarded & Retarded \\
\hline Argyria** & $0 \%$ & $0 \%$ & $0 \%$ & $0 \%$ \\
\hline Mortality*** & $0 \%$ & $20 \%$ & $0 \%$ & $0 \%$ \\
\hline
\end{tabular}

Notes: *Morbidity refers to the relative incidence of the disease in the animal. **Argyria refers to gray staining of the skin due to deposition of Ag. ***Mortality refers to death of the animals.

Abbreviations: MRSA, methicillin-resistant Staphylococcus aureus; AgNPs, silver nanoparticles. 

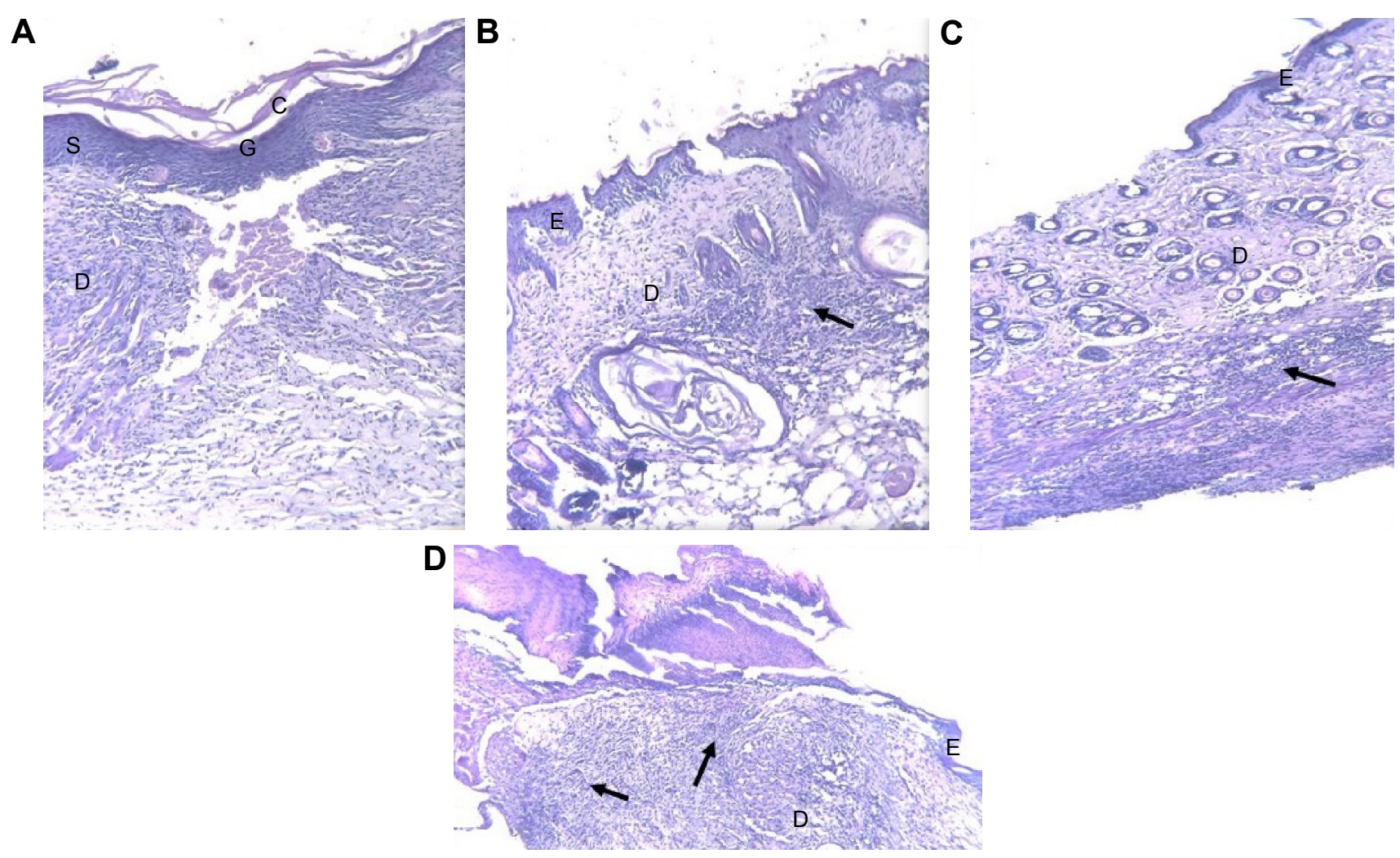

Figure 9 Light microscopy images of representative skin samples (stained with hematoxylin and eosin) $(\times 400)$ after I5 d of treatment: (A) $0.1 \%$ AgNPs hydrogel-treated group; (B) I\% silver sulfadiazine cream-treated group; (C) blank hydrogel-treated group; and (D) control group (untreated mice). Arrows refer to lymphocytes. C, G, S, D, and $\mathrm{E}$ represent stratum corneum, stratum granulosum, stratum spinosum, dermis, and epidermis, respectively.

Abbreviation: AgNPs, silver nanoparticles.

epidermis, complete restoration of epidermal layers, and complete basal, spinosum, granular, and cornfield layers (Figure 9A). Mild damage in the epidermal layers and incomplete healing were observed in the $1 \%$ silver sulfadiazine cream-treated skin (Figure 9B). In addition, slight infiltration of inflammatory cells (lymphocytes) was observed, which indicates a prolonged inflammatory response at the wound sites. ${ }^{76}$ In the representative skin samples from the blank hydrogel-treated group and control group, unhealed skin was clearly observed, where epidermis was severely damaged and no reformation was observed (Figure 9C and D). A varying degree of infiltration of inflammatory cells with accumulation of lymphocytes was observed, and damage was severe in both cases. In addition, severe focal dermal inflammation with intercellular edema was observed.

Skin samples from mice group that was treated daily with $0.1 \%$ AgNPs-loaded 3\% Na CMC hydrogel for $15 \mathrm{~d}$ were examined under TEM. The uptake, distribution, and localization of AgNPs in the epidermal layers are demonstrated in the micrographs (Figure 10A and B), while localization of the AgNPs inside the Langerhans cell (antigen-presenting immune cells) is indicated in the stratum spinosum layer (Figure 10C).

\section{Conclusion}

In the current work, fungi-assisted biological reduction of $\mathrm{AgNO}_{3}$ solution resulted in spherical-shaped AgNPs with small and homogenous size, which were coated with several materials prior to formulation into hydrogels suitable for topical applications. Coating of the nanoparticles with PEG reduced the sedimentation rate of particles in their aqueous dispersions and greatly enhanced the shelf-life stability over 9 months. AgNPs dispersions were effective against both Gram-positive (MRSA and MSSA) and Gramnegative (E. coli) bacteria with preferential inhibitory effect against Gram-positive bacteria. Homogenous hydrogels were prepared using various gelling agents, where $\mathrm{NaCMC}$ hydrogel loaded with 10 mM PEG-coated AgNPs showed superior characteristics based on the viscosity, spreadability, and release studies, and therefore, was selected for further in vivo studies. $\mathrm{Na}$ CMC hydrogel loaded with $0.1 \% 10 \mathrm{mM}$ PEG-coated AgNPs showed superior in vivo antibacterial activity and wound healing with good skin appearance and normal hair growth when tested on MRSA-infected wound mice model as compared to the commercially available $1 \%$ silver sulfadiazine cream. Complete restoration of the epidermal layers in the mice skin treated with the AgNPs 

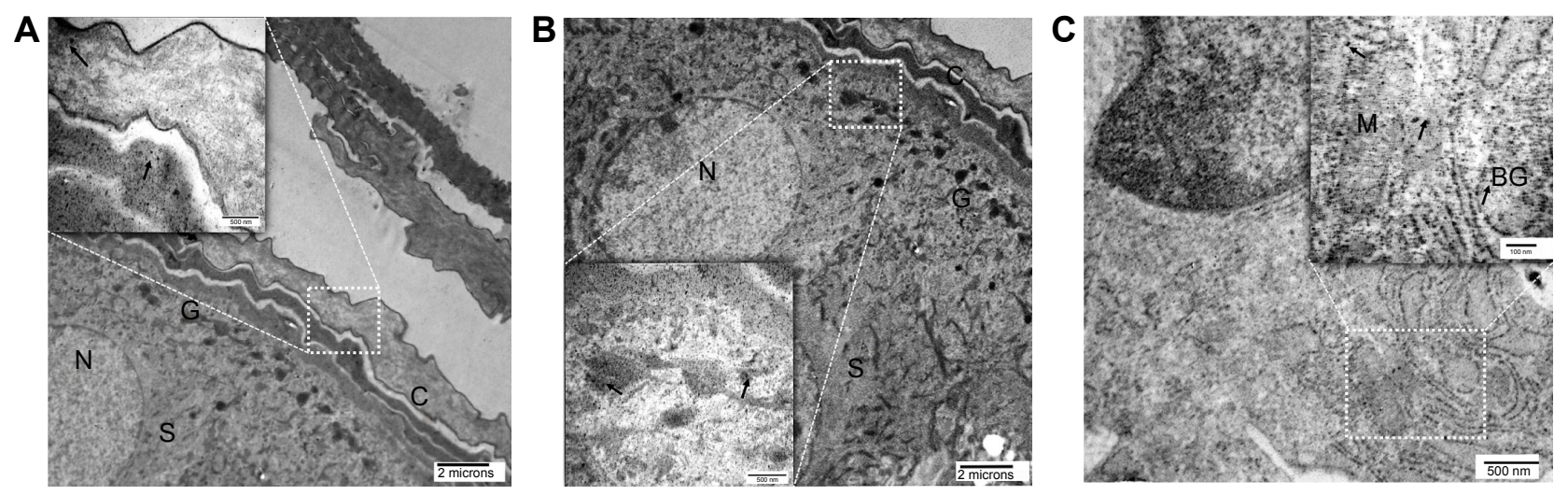

Figure 10 Transmission electron micrographs: (A) epidermal layers with magnification of stratum corneum; (B) epidermal layers with magnification of stratum granulosum $(\times 4,800$, inset: $\times 29,000)$, (C) Langerhans cell in stratum spinosum $(\times 19,000$, inset: $\times 72,000)$. Inset arrows indicate localized AgNPs. C, G, S, N, BG, and M represent stratum corneum, stratum granulosum, stratum spinosum, nucleus, Birbeck granules, and mitochondria, respectively.

Abbreviation: AgNPs, silver nanoparticles.

hydrogel was demonstrated, and localization of the nanoparticles in the different epidermal layers was detected in the TEM micrographs of the treated skin. Lower toxicity and higher tolerability were observed in the mice treated with the AgNPs-loaded hydrogels as compared to the silver sulfadiazine cream-treated group as indicated in the animal experiments and histological studies.

\section{Acknowledgment}

The authors gratefully acknowledge Prof Dr Gamal H El-Sokkary (Faculty of Science, Assiut University, Egypt) for his valuable cooperation in the histological studies of the skin samples.

\section{Disclosure}

The authors report no conflicts of interest in this work.

\section{References}

1. Birla SS, Tiwari VV, Gade AK, Ingle AP, Yadav AP, Rai MK. Fabrication of silver nanoparticles by Phoma glomerata and its combined effect against Escherichia coli, Pseudomonas aeruginosa and Staphylococcus aureus. Lett Appl Microbiol. 2009;48(2):173-179.

2. Brandt O, Mildner M, Egger AE, et al. Nanoscalic silver possesses broadspectrum antimicrobial activities and exhibits fewer toxicological side effects than silver sulfadiazine. Nanomedicine. 2012;8(4):478-488.

3. Gurunathan S, Han JW, Kwon DN, Kim JH. Enhanced antibacterial and anti-biofilm activities of silver nanoparticles against Gram-negative and Gram-positive bacteria. Nanoscale Res Lett. 2014;9(1):373.

4. Keat CL, Aziz A, Eid AM, Elmarzugi NA. Biosynthesis of nanoparticles and silver nanoparticles. Bioresour Bioprocess. 2015;2(47):1-11.

5. Vasilev K, Cook J, Griesser HJ. Antibacterial surfaces for biomedical devices. Expert Rev Med Devices. 2009;6(5):553-567.

6. Webb GF, D'Agata EM, Magal P, Ruan S. A model of antibiotic-resistant bacterial epidemics in hospitals. Proc Natl Acad Sci U S A. 2005;102(37): 13343-13348

7. Bustos-Martínez JA, Hamdan-Partida A, Gutiérrez-Cárdenas M. Staphylococcus aureus: la reemergencia de un patógeno en la comunidad [Staphylococcus aureus: the reemergence of a pathogen in the community]. Rev Biomed. 2006;17:287-305. Spanish.
8. Ayala-Núñez NV, Villegas HHL, Turrent LdCI, Padilla CR. Silver nanoparticles toxicity and bactericidal effect against methicillin-resistant Staphylococcus aureus: nanoscale does matter. NanoBiotechnology. 2009;5(1):2-9.

9. Alexander JW. History of the medical use of silver. Surg Infect (Larchmt). 2009;10(3):289-292.

10. Jaiswal S, Duffy B, Jaiswal AK, Stobie N, McHale P. Enhancement of the antibacterial properties of silver nanoparticles using beta-cyclodextrin as a capping agent. Int J Antimicrob Agents. 2010;36(3):280-283.

11. Khatami M, Pourseyedi S, Khatami M, Hamidi H, Zaeifi M, Soltani L. Synthesis of silver nanoparticles using seed exudates of Sinapis arvensis as a novel bioresource and evaluation of their antifungal activity. Bioresour Bioprocess. 2015;2(19):1-7.

12. Li WR, Xie XB, Shi QS, Duan SS, Ouyang YS, Chen YB. Antibacterial effect of silver nanoparticles on Staphylococcus aureus. BioMetals. 2011;24(1):135-141.

13. Rai M, Yadav A, Gade A. Silver nanoparticles as a new generation of antimicrobials. Biotechnol Adv. 2009;27(1):76-83.

14. Gong $\mathrm{P}, \mathrm{Li} \mathrm{H}, \mathrm{He} \mathrm{X}$, et al. Preparation and antibacterial activity of $\mathrm{Fe}_{3} \mathrm{O}_{4} @ \mathrm{Ag}$ nanoparticles. Nanotechnology.2007;18(28):285604.

15. Percival SL, Bowler PG, Dolman J. Antimicrobial activity of silvercontaining dressings on wound microorganisms using an in vitro biofilm model. Int Wound J. 2007;4(2):186-191.

16. Pal S, Tak YK, Song JM. Does the antibacterial activity of silver nanoparticles depend on the shape of the nanoparticle? A study of the Gramnegative bacterium Escherichia coli. Appl Environ Microbiol. 2007; 73(6): 1712-1720.

17. Roe D, Karandikar B, Bonn-Savage N, Gibbins B, Roullet JB. Antimicrobial surface functionalization of plastic catheters by silver nanoparticles. J Antimicrob Chemother. 2008;61(4):869-876.

18. Zhao G, Stevens SJ Jr. Multiple parameters for the comprehensive evaluation of the susceptibility of Escherichia coli to the silver ion. BioMetals. 1998;11(1):27-32.

19. Kvitek L, Panáček A, Soukupová J, et al. Effect of surfactants and polymers on stability and antibacterial activity of silver nanoparticles (NPs). J Phys Chem C. 2008;112(15):5825-5834.

20. Rahisuddin, AL-Thabaiti SA, Khan Z, Manzoor N. Biosynthesis of silver nanoparticles and its antibacterial and antifungal activities towards Gram-positive, Gram-negative bacterial strains and different species of Candida fungus. Bioprocess Biosyst Eng. 2015;38(9):1773-1781.

21. Pérez-Díaz M, Alvarado-Gomez E, Magaña-Aquino M, et al. Anti biofilm activity of chitosan gels formulated with silver nanoparticles and their cytotoxic effect on human fibroblasts. Mater Sci Eng CMater Biol Appl. 2016;60:317-323.

22. Abid JP, Wark AW, Brevetb PF, Girault HH. Preparation of silver nanoparticles in solution from a silver salt by laser irradiation. Chem Commun (Camb). 2002;7(7):792-793. 
23. Andrade PF, de Faria AF, da Silva DS, Bonacin JA, Gonçalves Mdo C. Structural and morphological investigations of $\beta$-cyclodextrin-coated silver nanoparticles. Colloids Surf B Biointerfaces. 2014;118:289-297.

24. Jadhav K, Dhamecha D, Bhattacharya D, Patil M. Green and ecofriendly synthesis of silver nanoparticles: characterization, biocompatibility studies and gel formulation for treatment of infections in burns. J Photochem Photobiol B. 2016;155:109-115.

25. Kalishwaralal K, Deepak V, Ramkumarpandian S, Nellaiah H, Sangiliyandi G. Extracellular biosynthesis of silver nanoparticles by the culture supernatant of Bacillus licheniformis. Mater Lett. 2008;62(29): 4411-4413.

26. Nogueira PFM, Paino IMM, Zucolotto V. Nanosilver: properties, applications and impacts on health and environment. Vigil Sanit Debate. 2013;1(4):59-71.

27. Rowe RC, Sheskey PJ, Owen SC, editors. Handbook of Pharmaceutical Excipients. 5th ed. London: Pharmaceutical Press; 2006.

28. Stevenson AP, Blanco Bea D, Civit S, Antoranz Contera S, Iglesias Cerveto A, Trigueros S. Three strategies to stabilise nearly monodispersed silver nanoparticles in aqueous solution. Nanoscale Res Lett. 2012; 7(1):151.

29. Das A, Kumar A, Patil NB, Viswanathan C, Ghosh D. Preparation and characterization of silver nanoparticle loaded amorphous hydrogel of carboxymethylcellulose for infected wounds. Carbohydr Polym. 2015;130:254-261.

30. Naraginti S, Kumari PL, Das RK, Sivakumar A, Patil SH, Andhalkar VV. Amelioration of excision wounds by topical application of green synthesized, formulated silver and gold nanoparticles in albino Wistar rats. Mater Sci Eng C Mater Biol Appl. 2016;62:293-300.

31. Abdel-HafezSI,NafadyNA,Abdel-RahimIR, ShaltoutAM,MohamedMA. Biogenesis and optimisation of silver nanoparticles by the endophytic fungus Cladosporium sphaerospermum. Int J Nano Chem. 2016; 2(1):11-19.

32. Hoa LTM, Dung TT, Danh TM, Duc NH, Chien DM. Preparation and characterization of magnetic nanoparticles coated with polyethylene glycol. J Phys Conf Ser. 2009;187(1):012048.

33. Yu M, Huang S, Yu KJ, Clyne AM. Dextran and polymer polyethylene glycol (PEG) coating reduce both 5 and $30 \mathrm{~nm}$ iron oxide nanoparticle cytotoxicity in 2D and 3D Cell Culture. Int J Mol Sci. 2012;13(5): 5554-5570.

34. Clinical and Laboratory Standards Institute (CLSI). Methods for dilution antimicrobial susceptibility tests for bacteria that grow aerobically; approved standard-ninth edition. Vol 32. CLSI document M07-A9. Wayne, PA: CLSI; 2012.

35. Kora AJ, Manjusha R, Arunachalam J. Superior bactericidal activity of SDS capped silver nanoparticles: synthesis and characterization. Mater Sci Eng C Mater Biol Appl. 2009;29(7):2104-2109.

36. Thekkae Padil VV, Černík M. Green synthesis of copper oxide nanoparticles using gum karaya as a biotemplate and their antibacterial application. Int J Nanomedicine. 2013;8:889-898.

37. Islam MT, Rodríguez-Hornedo N, Ciotti S, Ackermann C. Rheological characterization of topical carbomer gels neutralized to different $\mathrm{pH}$. Pharm Res. 2004;21(7):1192-1199.

38. Jungermann E, Sonntag NOV, editors. Glycerine: A Key Cosmetic Ingredient. New York: Marcel Dekker, Inc; 1991.

39. Schmolka IR. Artificial skin. I. Preparation and properties of pluronic F-127 gels for treatment of burns. J Biomed Mater Res. 1972;6(6): $571-582$.

40. El-Houssieny BM, Hamouda HM. Formulation and evaluation of clotrimazole from pluronic F127 gels. Drug Discov Ther. 2010;4(1):33-43.

41. Dai T, Tegos GP, Zhiyentayev T, Mylonakis E, Hamblin MR. Photodynamic therapy for methicillin-resistant Staphylococcus aureus infection in a mouse skin abrasion model. Lasers Surg Med. 2010;42(1): $38-44$.

42. Tian J, Wong KK, Ho CM, et al. Topical delivery of silver nanoparticles promotes wound healing. ChemMedChem. 2007;2(1):129-136.
43. Ali SM, Yousef NMH, Nafady NA. Application of biosynthesized silver nanoparticles for the control of land snail Eobania vermiculata and some plant pathogenic fungi. J Nanomater. 2015;2015(3):1-10.

44. SPSS for windows, release 17.0.0 [computer program]. Chicago, IL: SPSS Inc; 2008.

45. Shenashen MA, El-Safty SA, Elshehy EA. Synthesis, morphological control, and properties of silver nanoparticles in potential applications. Part Part Syst Charact. 2014;31(3):293-316.

46. Ahmad A, Mukherjee P, Senapati S, et al. Extracellular biosynthesis of silver nanoparticles using the fungus Fusarium oxysporum. Colloids Surf B Biointerfaces. 2003;28(4):313-318.

47. Durán N, Marcato PD, Alves OL, Souza GI, Esposito E. Mechanistic aspects of biosynthesis of silver nanoparticles by several Fusarium oxysporum strains. J Nanobiotechnology. 2005;3:8.

48. Kumar SA, Abyaneh MK, Gosavi SW, et al. Nitrate reductase-mediated synthesis of silver nanoparticles from $\mathrm{AgNO}_{3}$. Biotechnol Lett. 2007; 29(3):439-445.

49. Vigneshwaran N, Kathe AA, Varadarajan PV, Nachane RP, Balasubramanya RH. Biomimetics of silver nanoparticles by white rot fungus, Phaenerochaete chrysosporium. Colloids Surf B Biointerfaces. 2006;53(1):55-59.

50. Premasudha P, Venkataramana M, Abirami M, Vanathi P, Krishna K, Rajendran R. Biological synthesis and characterization of silver nanoparticles using Eclipta alba leaf extract and evaluation of its cytotoxic and antimicrobial potential. Bull Mater Sci. 2015;38(4):965-973.

51. Ma R, Levard C, Marinakos SM, et al. Size-controlled dissolution of organic-coated silver nanoparticles. Environ Sci Technol. 2012;46(2): 752-759.

52. Dounighi MN, Eskandari R, Avadi MR, Zolfagharian H, Mir Mohammad Sadeghi A, Rezayat M. Preparation and in vitro characterization of chitosan nanoparticles containing Mesobuthus Eupeus scorpion venom as an antigen delivery system. J Venom Anim Toxins Incl Trop Dis. 2012; 18(1):44-52.

53. Sahu BP, Das MK. Preparation and in vitro/in vivo evaluation of felodipine nanosuspension. Eur J Drug Metab Pharmacokinet. 2014;39(3): 183-193.

54. Sundararajan B, Mahendran G, Thamaraiselvi R, Kumari BR. Biological activities of synthesized silver nanoparticles from Cardiospermum halicacabum L. Bull Mater Sci. 2016;39(2):423-431.

55. Li X, Lenhart JJ, Walker HW. Aggregation kinetics and dissolution of coated silver nanoparticles. Langmuir. 2012;28(2):1095-1104.

56. Stiufiuc R, Iacovita C, Lucaciu CM, et al. SERS-active silver colloids prepared by reduction of silver nitrate with short-chain polyethylene glycol. Nanoscale Res Lett. 2013;8(1):47.

57. Ansari MA, Khan HM, Khan AA, et al. Evaluation of antibacterial activity of silver nanoparticles against MSSA and MRSA on isolates from skin infections. Biol Med. 2011;3(2):141-146.

58. Martínez-Castañón GA, Niño-Martínez N, Martínez-Gutierrez F, Martínez-Mendoza JR, Ruiz F. Synthesis and antibacterial activity of silver nanoparticles with different sizes. J Nanopart Res. 2008;10(8): $1343-1348$.

59. Thiel J, Pakstis L, Buzby S, et al. Antibacterial properties of silver-doped titania. Small. 2007;3(5):799-803.

60. Kim JS, Kuk E, Yu KN, et al. Antimicrobial effects of silver nanoparticles. Nanomedicine. 2007;3(1):95-101.

61. Shrivastava S, Bera T, Roy A, Singh G, Ramachandrarao P, Dash D. Characterization of enhanced antibacterial effects of novel silver nanoparticles. Nanotechnology. 2007;18(22):225103.

62. Ojha AK, Forster S, Kumar S, Vats S, Negi S, Fischer I. Synthesis of well-dispersed silver nanorods of different aspect ratios and their antimicrobial properties against Gram positive and negative bacterial strains. J Nanobiotechnology. 2013;11:42.

63. Ruparelia JP, Chatterjee AK, Duttagupta SP, Mukherji S. Strain specificity in antimicrobial activity of silver and copper nanoparticles. Acta Biomater. 2008;4(3):707-716. 
64. Guvendiren M, Lu HD, Burdick JA. Shear-thinning hydrogels for biomedical applications. Soft Matter. 2012;8(2):260-272.

65. Mekkawy A, Fathy M, El-Shanawany S. Formulation and in vitro evaluation of fluconazole topical gels. Br J Pharm Res. 2013;3(3):293-313.

66. Bibby DC, Davies NM, Tucker IG. Mechanisms by which cyclodextrins modify drug release from polymeric drug delivery systems. Int J Pharm. 2000;197(1-2):1-11.

67. Izawa H, Kawakami K, Sumita M, Tateyama Y, Hill JP, Ariga K. $\beta$-Cyclodextrin-crosslinked alginate gel for patient-controlled drug delivery systems: regulation of host-guest interactions with mechanical stimuli. J Mater Chem B. 2013;1(16):2155-2161.

68. Sajomsanga W, Nuchuchuaa O, Gonila P, et al. Water-soluble $\beta$-cyclodextrin grafted with chitosan and its inclusion complex as a mucoadhesive eugenol carrier. Carbohydr Polym. 2012;89(2):623-631.

69. Challa R, Ahuja A, Ali J, Khar RK. Cyclodextrins in drug delivery: an updated review. AAPS PharmSciTech. 2005;6(2):E329-E357.

70. Diegelmann RF, Evans MC. Wound healing: an overview of acute, fibrotic and delayed healing. Front Biosci. 2004;9:283-289.
71. Liu X, Lee PY, Ho CM, et al. Silver nanoparticles mediate differential responses in keratinocytes and fibroblasts during skin wound healing. ChemMedChem. 2010;5(3):468-475.

72. Franková J, Pivodová V, Vágnerová H, Juráňová J, Ulrichová J. Effects of silver nanoparticles on primary cell cultures of fibroblasts and keratinocytes in a wound-healing model. J Appl Biomater Funct Mater. 2016; 14(2):e137-e142.

73. Szmyd R, Goralczyk AG, Skalniak L, et al. Effect of silver nanoparticles on human primary keratinocytes. Biol Chem. 2013;394(1):113-123.

74. Nam G, Rangasamy S, Purushothaman B, Song JM. The application of bactericidal silver nanoparticles in wound treatment. Nanomater Nanotechnol. 2015;5(23):1-14.

75. Hendi A. Silver nanoparticles mediate differential responses in some of liver and kidney functions during skin wound healing. J King Saud Univ Sci. 2011;23(1):47-52.

76. Pène J, Chevalier S, Preisser L, et al. Chronically inflamed human tissues are infiltrated by highly differentiated Th17 lymphocytes. J Immunol. 2008;180(11):7423-7430
International Journal of Nanomedicine

\section{Publish your work in this journal}

The International Journal of Nanomedicine is an international, peerreviewed journal focusing on the application of nanotechnology in diagnostics, therapeutics, and drug delivery systems throughout the biomedical field. This journal is indexed on PubMed Central, MedLine, CAS, SciSearch ${ }^{\circledR}$, Current Contents $₫ /$ Clinical Medicine,

\section{Dovepress}

Journal Citation Reports/Science Edition, EMBase, Scopus and the Elsevier Bibliographic databases. The manuscript management system is completely online and includes a very quick and fair peer-review system, which is all easy to use. Visit http://www.dovepress.com/ testimonials.php to read real quotes from published authors. 